\title{
Symptomatic Treatment of Multiple Sclerosis
}

\section{Multiple Sclerosis Therapy Consensus Group (MSTCG) of the German Multiple Sclerosis Society ${ }^{1}$}

\author{
T. Henze ${ }^{a} \quad$ P. Rieckmann ${ }^{b} \quad$ K.V. Toyka ${ }^{b}$ \\ ${ }^{a}$ Reha-Zentrum Nittenau, Rehabilitationszentrum für Neurologie, Nittenau, and ${ }^{b}$ Department of Neurology, \\ University of Würzburg, Würzburg, Germany
}

\section{Key Words}

Multiple sclerosis $\cdot$ Symptomatic treatment $\cdot$ Consensus guidelines $\cdot$ Expert opinion $\cdot$ Evidence-based medicine

\begin{abstract}
Besides immunomodulation and immunosuppression, the specific treatment of symptoms is an essential component of the overall management of multiple sclerosis (MS). Symptomatic treatment is aimed at the elimination or reduction of symptoms impairing the functional abilities and quality of life of the affected patients. Moreover, with symptomatic treatment the development of a secondary physical impairment due to an existing one may be avoided. Many therapeutic techniques as well as different drugs are used for the
\end{abstract}

treatment of MS symptoms, but only a few of them have been investigated, especially in MS patients, and are approved by the national health authorities. Despite an overwhelming number of publications, only a few evidencebased studies exist and consensus reports are very rare, too. Therefore, it seemed necessary to develop a consensus statement on symptomatic treatment of MS comprising existing evidence-based literature as well as therapeutic experience of neurologists who have dealt with these problems over a long time. This consensus paper contains proposals for the treatment of the most common MS symptoms: disorders of motor function and coordination, of cranial nerve function, of autonomic, cognitive, and psychological functions as well as MS-related pain syndromes and epileptic seizures.

Copyright $\odot 2006$ S. Karger AG, Basel
1 Members of the MSTCG and the Writing Group are: Switzerland: C. Bassetti (Zürich), K. Beer (St. Gallen), S. Beer (Valens), U. Buettner (Aarau), M. Chofflon (Genf), M. Götschi-Fuchs (Knoblisbühl), K. Hess (Zürich), L. Kappos (Basel), J. Kesselring (Valens), H.-P. Ludin (St. Gallen), H. Mattle (Bern), M. Schluep (Lausanne), C. Vaney (Montana-Vermala). Austria: U. Baumhackl (St. Pölten), T. Berger (Innsbruck), F. Deisenhammer(Innsbruck), F. Fazekas (Graz), M. Freimüller(Hermagor), H. Kollegger (Wien), W. Kristoferitsch (Wien), H. Lassmann (Wien), H. Markut (Vöcklabruck), S. Strasser-Fuchs (Graz), K. Vass (Wien). Germany: H. Albrecht (Berg), H. Altenkirch (Berlin), A. Bayas (Augsburg), R. Benecke (Rostock), W. Brück (Göttingen), M. Buttmann (Würzburg), A. Chan (Göttingen), M. Daumer (München), D. Dommasch (Bielefeld), W.G. Elias (Hamburg), E. Fasshauer (Thüringen), W. Feneberg (Berg), P. Flachenecker (Bad Wildbad), C. Frischholz (Würzburg), A. Gass (Mannheim/Basel), W. Gehlen (Bochum), N. Goebels (Zürich), R. Gold (Bochum), J. Haas (Berlin), G. Haferkamp (Hannover), P. Haller (Osnabrück), H.-P. Hartung (Düsseldorf), M. Haupts (Bochum), C. Heesen (Hamburg), M. Heibel (Hachen), F. Heidenreich (Hannover), B. Hemmer (Düsselddorf), T. Henze
(Nittenau), R. Hohlfeld (München), R.W.C. Janzen (Frankfurt/Main), S. Jung (Homburg), E. Jügelt (Sundern/Hachen), B. Kallmann (Würzburg), B. Kieseier (Düsseldorf), C. Kleinschnitz (Würzburg), J. Köhler (Mainz), W. Kölmel (Erfurt), N. König (Berg), G. Lehrieder (Bad Windsheim), V. Leussink (Düsseldorf), K. Lowitzsch (Ludwigshafen), M. Mäurer (Würzburg/Erlangen), U. Manegold (Göttingen), A. Melms (Tübingen), J. Mertin (Amtzell), O. Neuhaus (Düsseldorf), P. Oschmann (Gießen), H.-F. Petereit (Köln), M. Pette (Dresden), D. Pöhlau (Asbach), W. Pöllmann (Berg), D. Pohl (Göttingen/Zürich), P. Rieckmann (Würzburg), K. Ruprecht (Würzburg/Homburg), M. Sailer (Magdeburg), H. Schipper (Bernburg), S. Schmidt (Bonn), G. Schock (Gera), M. Schulz (Ueckermünde), S. Schwarz (Mannheim), G. Schwendemann (Bremen), D. Seidel (Isselburg), N. Sommer (Marburg), M. Starck (Berg), M. Stangel (Hannover), E. Stark (Offenbach), A. Steinbrecher (Regensburg), G. Stoll (Würzburg), K.V. Toyka (Würzburg), H. Tumani (Ulm), R. Voltz (Köln), K.-P. Wandinger (Berlin), F. Weber(München), F. Weilbach (Bad Kissingen), W. Weinrich (Hannover), R. Weissert (Tübingen), H. Wiendl (Würzburg), H. Wiethölter (Stuttgart), U.K. Zettl (Rostock), F. Zipp (Berlin), R. Zschenderlein (Berlin).

\section{KARGER}

Fax +41613061234 E-Mail karger@karger.ch www.karger.com
(C) 2006 S. Karger AG, Basel

0014-3022/06/0562-0078\$23.50/0

Accessible online at:

www.karger.com/ene
T. Henze, MD

Reha-Zentrum Nittenau, Rehabilitationszentrum für Neurologie

Eichendorffstrasse 21, DE-93149 Nittenau (Germany)

Tel. +499436950 800, Fax +499436950818

E-Mail t.henze@rz-ni.de 


\section{Introduction}

Since 1999, several evidence-based treatment recommendations on immunomodulatory and immunosuppressive treatment of multiple sclerosis (MS) have been published by the Multiple Sclerosis Treatment Consensus Group (MSTCG), representing members of the Medical Advisory Boards from MS Societies of Austria, Germany and Switzerland [1-4]. These recommendations include both evidence-based knowledge and expert opinions where sufficient data from clinical trials are not yet available. The MSTCG recommendations have recently been updated and were published after approval by the Medical Advisory Boards of the Austrian, German, and Swiss MS societies and of an additional eleven European countries [1]. This paper also comments on some other current issues regarding diagnosis and standardized follow-up of MS patients. Meanwhile, these guidelines have proven to help practicing physicians by providing standards in the treatment of MS patients, especially when unequivocal scientific evidence is lacking and expert opinion is needed.

MS is characterized by numerous symptoms and signs that result from MS-related pathology and dysfunction and are not amenable to immunotherapy. Although there is a vast amount of scientific literature dealing with symptomatic MS treatment, high-quality studies are still scarce. Therefore, the MSTCG developed and published consensus guidelines based on the available evidence from clinical studies and on expert opinion collected and critically edited by a group of MS neurologists [5]. This review includes treatment guidelines for some of the most important MS symptoms:

- Motor function and coordination, e.g. spasticity, pareses, ataxia, and tremor

- Cranial nerves, e.g. diplopia, nystagmus, dysarthria, dysphagia

- Autonomic nervous system function, e.g. bladder, bowel, and sexual dysfunction

- Psychiatric and psychological problems, e.g. depression; disturbances of cognitive function, and fatigue

- Pain and paroxysmal symptoms including epileptic seizures.

The importance of symptomatic treatment and rehabilitation for MS has recently been discussed in detail by the European Multiple Sclerosis platform [6] and the European Council for Treatment and Research in MS (ECTRIMS).

The aim of symptomatic MS therapy is to eliminate or ameliorate symptoms affecting the patients' functional abilities impairing quality of life. Moreover, secondary impairment or disability is to be avoided, including those due to contractures or pain caused by severe spasticity, or by lumbar disc degeneration and chronic immobility or joint degeneration due to gait disturbances. Ascending infections following impaired bladder function are equally important.

Many drugs and treatment methods that are widely used in the treatment of MS symptoms are still 'off-label' in most countries. Many have never been investigated in proper clinical trials in MS patients, and were not approved by the respective national or European health authorities. In addition, several treatment modalities, e.g. some antiepileptic drugs for 'neuropathic' pain, intrathecal triamcinolone acetonide for spasticity, or 4-aminopyridine to treat fatigue or heat intolerance, are being used and evaluated in MS centers and specialized hospitals but the financial impact and legal burdens often prevent pharmaceutical companies from filing an application for licensure. Thus, in the near future, health insurance companies may no more reimburse the costs of these drugs due to their off-label status, thus cutting these patients off from such treatment.

An important prerequisite for an effective symptomatic treatment is the proper classification of symptoms presented by the MS patient. As an example, there are different types of MS-related pain which have to be treated according to the presumed pathogenic mechanisms. The same holds true for bladder dysfunction, tonic spasticity, dysphagia, and others.

Therefore, consensus guidelines for the treatment of MS symptoms are urgently needed in order to preserve these important treatment modalities which should be available at least for physicians with special experience in the treatment of MS patients. It is hoped that the national agencies and insurance companies will accept consensus statements of this kind to allow reimbursement. It seems unlikely for many treatment modalities to ever undergo a full clinical trial in MS patients providing 'gold standard' type evidence (class I evidence according to the criteria published by the American Academy of Neurology [7]): (1) many of these modalities meet little interest of the pharmaceutical industry because they are of low marketing value in MS-related indications; (2) several approaches involve combination therapies which, in the absence of approval of all single components, are not amenable to FDA- or EMEA-approved treatment trials. 


\section{Methods}

We performed an extensive Medline Search covering publications on all symptoms which have been dealt with in this article combined with 'multiple sclerosis' during the period from 1980 to May 2005 and then rated the references found for the respective category of evidence classes I-III; class I denoting evidence by one or more randomized controlled studies; class II: evidence by one or more well-documented clinical studies like case-control studies or cohort studies; class III: evidence by not randomized historical controls, case reports, or expert opinion. This is followed by a classification of the different treatment options into the types of recommendation $\mathrm{A}, \mathrm{B}, \mathrm{C}$, and $\mathrm{U}$, whereby $\mathrm{A}$ represents the strongest and $U$ the weakest type of recommendation [7]. We added the item 'expert opinion' denoting treatments which have so far never been and probably will never be investigated on a high evidence level, but have proven to be effective from independent experts' clinical experience.

\section{Spasticity}

Spasticity in MS is caused by axonal degeneration or malfunction that may be combined with demyelinating plaques within specific descending spinal tracts. This leads to a disturbance of inhibitory interneuronal spinal network pathways and results predominantly in weakness of physiological flexor muscles, usually with increased ('spastic') muscle tone and reduced dexterity of the muscles involved. Many types of bladder dysfunction in MS are also caused by spasticity of detrusor and sphincter muscles. For clinical purposes spasticity may be classified into a tonic (with persistently elevated muscle tone) and a phasic form (with intermittently elevated muscle tone) often associated with painful cramps. In patients with severe and long-standing spasticity contractures, disturbed micturition and bowel emptying all result in nursing restrictions and impair activities and quality of daily life. On the other hand, spasticity may to a certain degree help to ameliorate muscle weakness which reduces stability of lower limbs.

Aims of treatment include:

- Elimination or avoidance of triggers which may initiate or enhance spasticity such as urogenital infections, constipation, pain, fever or pressure sores, as well as information and training for appropriate posture, positioning and body transfer

- Amelioration of motor function

- Pain reduction

- Facilitation of nursing

- Avoidance of complications like contractures and pressure sores.

\section{Specific Treatments}

\section{Physiotherapy}

Physiotherapy is generally accepted as a basic treatment option for spasticity, even if controlled studies have only rarely been performed in patients with MS or other central nervous system disorders including stroke or spinal cord injury. To our knowledge, only one study examined the effect of physiotherapy in MS-related gait disturbances. This study reported positive results (class II evidence [8]). The most common techniques, e.g. those by Bobath, Vojta, and proprioceptive neuromuscular facilitation appear to be of roughly equal efficacy, despite their different rationale [9].

Passive treatment with an isokinetic apparatus was shown to lower spastic hypertonia in legs in patients after stroke (class II evidence [10]). Moreover, treadmill training with partial body weight support, combined with Vojta-type physiotherapy, was claimed to reduce spasticity in MS patients (class III evidence [11]). Moreover, repetitive training of isolated movements may also reduce spasticity in a paretic hand (class II evidence [12]).

There are other 'passive' treatment modalities capable of lowering elevated muscle tone like specific posturing of spastic limbs during rest in the supine position or in bed-bound patients, a slowly increasing tonic extension of spastic muscles, passive mobilization of joints using motor-driven bicycles several times a day, and use of dynamic or static splints [13]. The transient beneficial effect of cooling on elevated muscle tone was well worked out [14]. Hydrotherapy, too, has proven to reduce spasticity and the need for baclofen in patients with spinal cord injury [15].

\section{Drug Treatment}

Spasticity can be ameliorated by antispastic drugs, but its efficacy needs to be demonstrated by available scores. Unfortunately, these tests have their limits in the assessment of the overall effects [16]. The drugs should be given in divided doses according to the degree and daily fluctuations of spasticity, for example 30-45 min before getting up in the morning, frequent and regular dosage, or one dose before sleep. The most effective dosage has often to be 'titrated' carefully. Rapid discontinuation of a drug should be avoided because of possible rebound effects.

Oral drug treatment: The antispastic drugs most often used orally are baclofen and tizanidine, and both particularly reduce 'spinal spasticity'. For tizanidine (2-24 mg/day p.o., class I evidence $[17,18])$ and baclo- 
fen $10-120 \mathrm{mg}$ /day p.o., class II evidence [19-21]), sufficient evidence is available to support their use, whereas dantrolene and tolperisone were not tested appropriately and therefore are used as second-line drugs. Patients undergoing antispastic treatment with these drugs often report reduced spasticity and spasticity-related pain or clonus, especially at night [22].

The strong antispastic effects of benzodiazepines are well substantiated, but their profound side effects including sedation and dependence limit their use in MS [16, $22]$. The new drug gabapentin (300-3,600 mg/day), extensively studied in epilepsy and neuropathic pain syndromes, was shown to be effective in treating phasic spasticity (class I evidence $[23,24]$ ). Unfortunately, a direct comparison between gabapentin and the established antispastic drugs is missing.

Tetrahydrocannabinol (THC) or a cannabis extract were considered candidates to relieve spasticity. In a recent placebo-controlled trial with THC in 630 patients, no significant reduction of spasticity could be found when using the Ashworth Scale. Nevertheless, the therapeutic effects on patients' overall mobility and on the subjective impression of pain reduction with THC and with cannabis extract suggest a potential usefulness of these drugs (class I evidence [25]). The latter observations have been confirmed in some smaller studies [26-28]. Based on the available evidence, the use of cannabinoids cannot be recommended, except in single refractory cases as second-line treatment when the treatment is performed by physicians with a high level of experience. The dose-dependent side effects are that of other THC products and the problem of drug dependence has not been formally studied.

Botulinum toxin is an important recent addition to the treatment of spasticity, and may especially be valuable in reducing focal limb spasticity (e.g. of adductor muscles). Two randomized, placebo-controlled studies using the commercial preparations Botox ${ }^{\circledR}$ (class II evidence [29]) or Dysport ${ }^{\circledR}$ (class I evidence [30]) demonstrated a significant reduction of spasticity in adductor muscles compared to placebo. But with higher Dysport doses $(1,500$ units) more adverse effects occurred compared to injections of 1,000 or 500 units [30].

For a discussion of the use of botulinum toxin in treating spastic bladder disorders, see section on 'Neurogenic bladder dysfunction'.

Intrathecal baclofen: The efficacy of continuous intrathecal baclofen infusion via an implantable pump has been demonstrated convincingly in patients with MS and severe spasticity of spinal and supraspinal origin (class II evidence [31, 32]). Intrathecal baclofen results in a significant reduction of muscle tone and frequency of spasms and thereby has the potential to ameliorate quality of life. Unfortunately, the dose-dependent adverse effects including muscle weakness, headache, disturbance of consciousness and infections or dislocation of the catheter can be severe and even life-threatening. Therefore, continuous and skilled medical care in specialized centers is needed.

Intrathecal injection of corticosteroids (triamcinolone acetonide): This mode of treatment has been performed in some MS centers since the 1980s, but there is only limited evidence of its efficacy in spasticity of spinal origin. Moreover, no controlled studies have been performed so far comparing intrathecal triamcinolone acetonide with high-dose intravenous corticosteroids. There is only one recent follow-up study examining the effect of repeated intrathecal triamcinolone injections $(40 \mathrm{mg}$ every $3 \mathrm{rd}$ day, up to 6 times). This treatment resulted in a significant improvement of the EDSS and of walking distance. Serious side effects were not observed (class III evidence [33]). With respect to the invasive nature of treatment and the limited data available it can be recommended to be applied only by experienced neurologists.

\section{Recommendations}

- Search for hidden problems, which may increase spasticity (e.g. urinary tract infection, pain, fever).

- The mainstay of antispastic treatment is regular and intensive physiotherapy (expert opinion).

- If spasticity cannot be controlled sufficiently by physical therapy alone, baclofen or tizanidine should be given. Daily doses should be gradually increased and the maintenance dose adjusted according to the individual patient's course and severity of spasticity during the day (type A recommendation). Gabapentin may be effective, too (type A recommendation). Other oral antispastic drugs such as benzodiazepines and dantrolene should be used only as second-line treatment and on short term due to their common adverse effects.

- In severe spasticity of adductor muscles, treatment with botulinum toxin is helpful (type A recommendation). Continuous intrathecal baclofen infusion should be used only in cases with severe and otherwise uncontrollable spinal spasticity (type A recommendation).

- Application of oral cannabinoids and of intrathecal triamcinolone acetonide outside prospective clinical trials should be restricted to centers with special experience (expert opinion). 


\section{Fatigue}

Up to $75 \%$ of MS patients suffer at some stage during their disease from abnormal physical or cognitive fatigue which usually increases during the day. This MS fatigue is different from common exhaustion or tiredness and limits their professional activities and social life, sometimes as the most important impairment in an individual. Heat often aggravates fatigue (Uhthoff phenomenon). Depression may be often masked by symptoms of fatigue, and it therefore represents an important differential diagnosis, especially in early stages of MS. Some scales have been developed to quantify fatigue, for instance the $\mathrm{Fa}$ tigue Severity Scale (FSS [34]) and the modified Fatigue Impact Scale (MFIS [35]) which among themselves are only partially comparable [36]. The aims of treatment are the reduction of fatigue and the facilitation of normal activities in social and occupational life.

\section{Specific Treatment}

\section{Cooling, Lowering of Body Temperature}

Lowering of body temperature, physical training, rehabilitation and drug treatment have all been investigated [37]. Transient cooling of the body or of arms and legs using cold packs, cold baths or air-conditioning may improve postural stability and muscle strength of the legs (class II evidence [38]), gait (class III evidence [39]) and also fatigue (class III evidence [40]). Cooling garments may result in a better Multiple Sclerosis Functional Composite (MSFC, class II evidence [41]). It can result in a distinct reduction of fatigue and may last from 3045 min up to several hours. Studies on the practicability of using cooling garments in an outpatient situation are not yet available.

\section{Physical Training and Multimodal Rehabilitation}

Aerobic training can improve subjective health and physical strength but does not affect fatigue scores significantly (class III evidence [42, 43], class II evidence [44]). Physical exercise programs may be continued regularly over at least some months. Ambulatory or in-hospital multimodal rehabilitation programs over about 6 weeks, including physiotherapy, occupational and milieu therapy, will reduce fatigue and ameliorate quality of life (class II evidence [45], class III evidence [46], class III evidence [47]).

\section{Drug Treatment}

Oral drug treatment includes amantadine, 4-aminopyridine, 3,4-diaminopyridine, pemoline, L-carnitine, and modafinil.

Amantadine sulfate: This drug leads to a moderate amelioration of subjective fatigue and of concentration, memory and problem-solving compared with placebo. It is generally well tolerated in daily doses of $200-400 \mathrm{mg} /$ day (class I evidence [48], class II evidence [49]).

4-Aminopyridine (4-AP), 3,4-diaminopyridine (3,4$D A P)$ : Aminopyridines have been investigated in some smaller double-blind studies. 4-AP seems to be superior to 3,4-DAP in the amelioration of temperature-related MS symptoms [50]. Therapeutic safety is limited due to a small therapeutic window, adverse effects include nausea and epileptic seizures in rare cases and more so with 4AP. Up to now, neither 4-AP nor 3,4-DAP are licensed drugs in Europe, but may be manufactured on individual prescription by licensed pharmacists. Patient's written consent is necessary as in any other treatment with nonpharmaceutical chemicals.

This mode of treatment may be effective especially in temperature-related motor symptoms (Uhthoff's sign). In a double-blind and placebo-controlled study over 1 year, fatigue could be reduced and motor-evoked potentials were more pronounced especially with high 4-AP serum concentrations $(4-\mathrm{AP}>30 \mathrm{ng} / \mathrm{ml}$, class I evidence [51]). Moreover, motor functions increase (class III evidence [52]) and may result in an amelioration of the EDSS (class II evidence [53]). A slow-release formulation of 4AP proved to reduce fatigue (class II evidence [54]). Yet its possible effect on non-motor functions remains unknown.

Pemoline: This centrally acting stimulating drug has been shown to be effective to reduce fatigue in a dose of $75 \mathrm{mg}$, but to a lesser extent than amantadine. Lower doses $(18.5 \mathrm{mg})$ were not different from placebo, while higher doses $(>75 \mathrm{mg}$ ) may provoke severe adverse effects like impaired hepatic function, agitation, and sleep disturbances which may lead to drug withdrawal due to side effects [55].

L-Carnitine modulates mitochondrial metabolism of muscle fibers and is usually used to treat some metabolic muscle disorders. In MS-related fatigue, L-acetylcarnitine led to amelioration of different fatigue scales in $29 \%$ of patients compared to $21 \%$ of patients receiving amantadine (class I evidence [56]); up to now, these results have not been confirmed by other authors.

Modafinil: This $\alpha$-adrenergic drug was originally developed for the treatment of narcolepsy. It may reduce 
fatigue in doses from 200 to $400 \mathrm{mg} /$ day (class III evidence $[57,58]$ ). Important adverse effects include headache, dizziness, and agitation. A recent double-blind, placebo-controlled study by Stankoff et al. [59] could not detect any superiority of modafinil on various fatiguerelated parameters (class I evidence).

Further treatments: A small cross-over trial with aspirin has recently shown some benefit on fatigue in MS [60]. Interestingly, some of the large earlier trials using immunomodulating agents suggest that they may also reduce fatigue, but few of these trials formally included measurements of fatigue within the list of their secondary endpoints [61-63]. Although in one other study the effect of $\beta$-interferons and glatiramer acetate (GLAT) on fatigue was measured using the Fatigue Impact Scale, $24.8 \%$ of patients receiving GLAT reported a reduced degree of fatigue (class II evidence [64]).

Hyperbaric oxygen treatment was also claimed to be effective, but this was not confirmed beyond the point of short-lived effects [65]. The application of a caffeine and histamine containing unguent (Procaril) or of weak magnetic fields [66] on MS-related fatigue have been published; unfortunately none of them has been confirmed by others up to now; the latter was clearly disproved in a recent controlled trial [67].

\section{Recommendations}

- Exclusion of other treatable causes of fatigue-like depression or hypothyroidism.

- Cooling of the body or of extremities (type A recommendation).

- Drug treatment with amantadine (few adverse effects, type A recommendation). If insufficient effect: 4-AP (type A recommendation), L-acetylcarnitine (type $\mathrm{B}$ recommendation) or modafinil (expert opinion, type $U$ recommendation).

- Complementary: rehabilitation with energy-efficiency training (type B recommendation).

\section{MS-Related Pain Syndromes}

The frequency of clinically relevant pain is reported by 29 up to $86 \%$ of MS patients. These figures vary considerably due to different study design. MS-related pain may be classified into four main categories:

- Directly MS-related pain: Acute optic neuritis, headache due to a demyelinating lesion within the brainstem or cervical spinal cord, pseudoradicular pain; paroxysmal syndromes (trigeminal and other neuralgias including radicular pain syndromes, paroxysmal dystonia with painful muscle spasms, Lhermitte's sign); chronic painful dys- and paresthesias, thalamic pain.

- Pain as indirect sequel of other MS symptoms: Jointand muscle-related pain due to longstanding abnormal posture, spasticity, contractures, pressure sores, decubital ulcer; visceral pain; peripheral nerve lesions due to chronic pressure, e.g. poorly fitted ortheses.

- Pain following drug treatment, especially $\beta$-interferons.

- MS-independent pain: Chronic low back pain in the realm of degenerative spinal column diseases; osteoporosis, or primary headaches.

The limitation of this categorization lies in the fact that some of these pain syndromes, e.g. low back pain, may be classified into more than one group.

Only few evidence-based studies on treatment of MSrelated pain syndromes have been published. Thus, most treatments used today have been investigated in neuropathic and nociceptive pain resulting from other diseases. Duration, severity, accompanying symptoms, triggers and treatments used should be documented within a pain diary. Severity of pain may be estimated using a visual analogue scale. Treatment is aimed at reducing pain resulting in lesser restriction of mobility, ability and psychosocial sequels, and thus ameliorating quality of life.

\section{Specific Treatment}

The mode of treatment depends on the type of pain the patient presents and therefore its exact differentiation is crucial. Whenever possible, physiotherapy and occupational therapy should be used since they suggest an 'active action against pain'. If development of chronic pain is impending, an additive psychological treatment within a multimodal overall plan is indicated.

Directly MS-related pain: In acute optic neuritis, intravenous corticosteroids should be applied [1], mostly reducing pain within a short time. For treatment recommendations of neuralgias and paroxysmal dystonia, see section on 'Paroxysmal Symptoms'.

Directly MS-related chronic pain often presents with unpleasant 'burning' dysesthesias of arms, legs, or trunk. They may be bilaterally and asymmetrical. This neuropathic pain is present in different neurological disorders and can be alleviated effectively by tricyclic antidepressants like amitriptyline (25-150 mg/day) or antiepileptic 
agents like carbamazepine $(200-1,600 \mathrm{mg} /$ day, metaanalysis [68]). Similar effects can be achieved with gabapentin (300-2,400 $\mathrm{mg} /$ day) and lamotrigine (200$400 \mathrm{mg} /$ day; meta-analysis [69], class I-II evidence [70]) or pregabalin (150-600 mg/day; class I evidence [71, 72]). Neuropathic pain in MS patients has been ameliorated by gabapentin (300-2400 mg/day; class III evidence [73]) or topiramate (200-300 mg/day; class III evidence [74]).

If opioids are used in treatment escalation for central pain, high dosages are required in most cases [75] and will therefore not be tolerated by many on long-term treatment, e.g. morphine $9-30 \mathrm{mg} / \mathrm{day}$ (class II evidence [76]).

Serotonin reuptake inhibitors (SSRIs) appear not as effective as tricyclic antidepressants [68]. Newer antidepressants [77] like mirtazapine which indirectly enhance noradrenergic and serotonergic transmission, the dual serotonin-noradrenaline reuptake inhibitors venlafaxin (class II evidence [78, 79] and duloxetine [80] as well as the noradrenaline reuptake inhibitor reboxetine (class III evidence [81]) may in the near future offer some additional treatment options.

Up to now the impact of cannabinoids cannot be assessed precisely: In one study with the primary endpoint of reduction of MS-related spasticity, a significant amelioration of pain compared to placebo has been reported [25]. Unfortunately the type of pain was not been described in detail. In another study, dronabinol proved to be more effective in the treatment of MS-related central pain than placebo [82].

Pain as indirect sequel of MS: These pain syndromes mostly result from excessive burden of joints and muscles. They may present (1) as low back pain, knee or hip pain due to pronounced limping with central gait disorders, or (2) as radicular or pseudoradicular pain of cervical and lumbar spine.

The patients should be informed on the probable causal relation between pain and abnormal gait or posture. Moreover, they should be encouraged to actively work on acquiring a near-physiologic gait. Spasticity, if present, should be treated long term by physiotherapy and drug treatment. Mechanical aids (ortheses) when needed must be custom-fitted and tested when in use.

Chronic neck pain is often present in patients with pronounced muscular weakness and in wheelchairbound patients. In these cases, therapeutic exercises with 'proprioceptive re-education' is recommended for reduction of pain [83]. Manual therapy with spinal mobilization seems to be superior to conventional physiotherapy (class II evidence [84]). Shoulder pain may be alleviated convincingly by ultrasound treatment for calcified tendinopathy [83].

Drug treatment of these pain syndromes should follow published guidelines for therapy of degenerative arthropathies since no MS-specific studies exist [85].

Pain as well as painful sensory symptoms due to pressure lesions or chronic entrapment (e.g. of peroneal nerve), of carpal tunnel or sulcus ulnaris syndrome require adjustment of mechanical aids (splints, wheelchairs, sticks) completed by physiotherapy and occupational therapy, especially if pronounced ataxia or spasticity is present. Prevention of decubital ulcers requires optimization of posture, body position, and special beds and mattresses.

Pain following drug treatment: Local pain during treatment with $\beta$-interferons or GLAT may be prevented by application of cold packs before and after injection and by optimized mode of injection as indicated in the patient brochures. Flu-like symptoms with muscular pain can be alleviated with paracetamol, acetaminophen, ibuprofen, other non-steroidal antirheumatics or low-dose corticosteroids. The effectiveness of these drugs is widely comparable (class I evidence [86], class II evidence [87]). Increasing headache during $\beta$-interferon treatment may be reduced following published guidelines of the national headache societies.

MS-independent pain: The syndrome of 'low back pain' is present in up to $40 \%$ of MS patients due to one or several of the following: immobilization, muscle tenseness, spasticity of truncal muscles, osteoporosis, chronic degenerative disc disorders and vertebral joint disease. Again, physical therapy to optimize body posture and transfer is of general help associated with well-fitted ortheses where appropriate. In some studies, chronic lumbar pain physiotherapy has proven to be effective [88] as well as acupuncture massage which was claimed to be superior to conventional massage [89]. Drug treatment should be performed according to that for chronic neck and shoulder pain [85].

Lumbar, pelvic and iliosacral pain often are pseudoradicular in origin. In radicular pain, discherniation should be excluded. In osteoporosis, biphosphonates are the treatment of choice [90]. It should be kept in mind that repeated corticosteroid treatment at short intervals (e.g. monthly) is likely to aggravate osteoporosis.

In the complex situation of multiple pain states one should also consider surgical interventions, e.g. in profound disc protrusion or in a narrow spinal canal with possible spinal cord compression whenever this is likely to cause the pain syndrome. 


\section{Recommendations}

- Specific history with patient and caretakers for pain, since these symptoms may be underreported spontaneously. Documentation in a 'pain diary', differentiation of type of pain (expert opinion).

- For painful dysesthesias and neuropathic pain: amitriptyline or carbamazepine (type A recommendation), alternatively gabapentin, lamotrigine or pregabalin in gradually increasing doses (type A recommendation).

- For arthralgias, neck and shoulder pain: education and treatment on the role of abnormal posturing, optimization of mechanical aids (expert opinion). Individually supervised physiotherapy (type A recommendation). Drug treatment following published guidelines (type B recommendation).

- For flu-like symptoms and muscle pain during $\beta$-interferon therapy: acetaminophen (paracetamol) or other NSAID (type $B$ recommendation), for local pain cold packs (expert opinion). For increasing headache drug treatment following published guidelines of the national headache societies.

- For low back pain: physiotherapy (type A recommendation). Drug treatment following published guidelines (type $\mathrm{B} / \mathrm{C}$ recommendation).

- Newly appearing pain should be diagnosed and should not be attributed 'automatically' to MS. In most cases a longstanding and multidisciplinary treatment is necessary.

\section{Bladder Symptoms}

Neurogenic bladder dysfunction (NBD) will occur in up to $80 \%$ of patients during the course of MS and usually impairs quality of life considerably. Sometimes, NBD is even the presenting symptom of MS and in some patients it will be the sole clinical complaint.

Detrusor hyperactivity with restricted storage capacity, urgency, increased frequency of micturition, and incontinence are the most common types of NBD. Detrusor-sphincter-dyssynergia presents with urgency, delayed bladder emptying, retention of urine, and incontinence. A hypocontractile detrusor will cause incomplete bladder emptying with elevated residual volume.

NBD may induce recurrent urinary tract infections as well as disturbed sleep due to nocturia or abdominal pain thus increasing spasticity, too. After many years, NBD will often result in detrusor hyperreflexia with an obstructive component and the risk for kidney damage.

Since the type and degree of NBD may change over time, all procedures should be based on information derived from micturition diary, serum creatinine, urea, mi- crobiological examination, and regular measurement of residual volume. Uroflowmetry, sonography of the urinary tract and urodynamometry may help to differentiate the various pathologic mechanisms and to find proper treatment options. Cooperation with an experienced urologist is essential.

Goals of treatment are the amelioration of the bladder's storage capacity with a low-pressure storage of urine, complete voiding, reduction of micturition frequency, recovery of continence, and prevention of complications (e.g. recurrent urinary tract infections, damage of the upper urinary tract by septicemia, stone formation and reduced kidney function).

\section{Specific Treatment}

\section{Counselling, Aids}

Patients should be encouraged to keep a micturition diary, to drink adequately and regularly throughout the day (1.5-2 1/day) but not late at night, and, if a pathological residual volume is present, not to delay micturition in case of urgency. Bladder training (Cochrane Report [91]; class II evidence [92]) as well as toilet training [93] seem to be effective. Moreover, counselling on aids like insets, condom urinals or other devices to treat incontinence is useful.

\section{Physiotherapy}

Biofeedback and pelvic floor training may lead to a reduction of urgency and incontinence without normalization of urodynamic parameters during treatment [94, 95]. Combined pelvic floor training and electrical stimulation in 80 MS patients with low residual volume reduced micturition frequency, urgency and incontinence, especially in men (class III evidence [96]).

\section{Drug Treatment}

Drugs to reduce detrusor activity: Anticholinergic compounds: The positive effect of oxybutynin and tolterodine to reduce incontinence and urgency in hyperactive bladder has been proven in several studies with class I evidence (Cochrane Report [94, 97-100]). The anticholinergic side effects may be attenuated by symptomatic treatment, slow-release formulations, or a newly developed oxybutynin-containing matrix transdermal adhesive [101]. Trospium chloride (40-60 $\mathrm{mg} /$ day) is comparable to oxybutynin, but may cause fewer anticholinergic side effects. Propiverine ( $45 \mathrm{mg} /$ day) has a positive effect on detrusor hyperreflexia and has also fewer anticholinergic 
effects than oxybutynin. Adverse effects on the central nervous system seem to be less pronounced with trospium chloride or tolterodine than with oxybutynin ( 45 vs. 4 vs. $15 \mathrm{mg}$ [102]). Studies on flavoxate in patients with urge incontinence are only of class II evidence [103]. The new anticholinergic agents darifenacin (meta-analysis, class I evidence [104]) and solifenacin (class I evidence $[105,106])$ may reduce urgency, micturition frequency and incontinence effectively.

The $\alpha$-blocking agents alfuzosine and tamsulosine aim at reducing an elevated voiding obstruction of the bladder especially in patients with simultaneous detrusor hyperreflexia. Tamsulosine ( 0.4 resp. $0.8 \mathrm{mg}$ once daily) improves storage capacity and emptying of the bladder (class II evidence [107]). Antispastic agents: Baclofen has a positive effect in spastic or dyssynergic sphincter when given orally (class III evidence [108], class III evidence [109]). Because of its common systemic side effects, baclofen is only a second-line drug for treatment of overactive bladder unless low doses are effective.

Desmopressin, the antidiuretic hormone, effectively reduces nocturnal micturition frequency (class II evidence $[110,111])$ and may be helpful for patients attending social activities like theatre or concert. Desmopressin should only be given to patients with normal function of the heart and the kidneys. Dose should not exceed $20 \mu \mathrm{g}$ intranasally [112], then treatment is mostly free of side effects [113].

Treatment of acute bladder infection: In patients with NBD, bladder infections are common and should be treated with targeted antibiotics [114] for at least 10 days. Differentiation of bacteriuria versus unequivocal infection sometimes may be difficult because of coexisting sensory disturbances or urge incontinence. Laboratory findings including leukocyturia, elevated white blood cells and erythrocyte sedimentation rate or C-reactive protein may help to make the diagnosis. Due to the short resting time of urine within the bladder, the nitrite test may be falsely negative even with nitrite secreting bacteria.

Prophylaxis of recurrent bladder infection: Low intravesical pressure and low residual volume should be achieved in order to reduce the frequency of urinary tract infection [115]. For prophylaxis of infection, methenamine $(2 \times 1 \mathrm{~g} /$ day, class III evidence [116] $)$ and methionine $(3 \times 500 \mathrm{mg} /$ day, class III evidence [117]) can be used whereas the efficacy of cranberry juice is questionable. The most important risk factor for complicated bladder infections is a transurethral or suprapubic catheter. In these patients, methenamine is not helpful be- cause of its mechanism of action. Even in acidic urine $(\mathrm{pH}<6)$ it will take 30-90 min to release inhibitory concentrations of formaldehyde. Vitamin $\mathrm{C}$ has not shown to be effective [118]. The frequency of symptomatic bladder infections could not be reduced by chronic administration of cotrimoxazole [119].

The value of long-term antibiotic treatment is still debated [120] since this is likely to provoke selection of drug-resistant bacteria.

Invasive treatments: Intermittent aseptic catheterization with disposable catheters done 4-6 times/day is the treatment of choice in a hyperreflexive bladder with obstruction, but may also be effective in hypo/areflexive NBD [121]. Bacterial infection remains a risk and small skin or mucosal bleedings may occur.

In MS patients, catheterization may sometimes be difficult due to visual or sensory impairment, ataxia, or reduced cognitive function. Therefore a comprehensive training and supervision by a specialized nurse is mandatory [122]. Disposable catheters with integrated lubricants should be preferred when available.

Intermittent aseptic catheterization combined with drug-induced attenuation of the detrusor may be more effective than bladder emptying by trigger maneuvers, abdominal press or Credé maneuver with regard to longterm prognosis [123].

Intravesical treatment: In case of severe adverse effects of oral anticholinergics, these and other drugs such as vanilloids, capsaicin or resiniferatoxin may be administered directly into the bladder. Oxybutynin (class II evidence [124]) and trospium chloride (class II evidence [125]) have clearly shown to reduce involuntary detrusor contractions after intravesical instillation without causing unpleasant side effects. Intravesical instillation of anticholinergics may therefore be useful, especially in patients regularly performing intermittent self-catheterization.

The positive effect of intravesical capsaicin in patients with detrusor hyperreflexia could also be demonstrated in several studies (class II evidence [126]). Unfortunately, instillation is very painful. Resiniferatoxin is equally effective and causes much less pain (class III evidence [127]). Due to the limited existing data and major side effects, vanilloids cannot be recommended at present.

Continuous bladder catheter: Due to their high rate of side effects, e.g. chronic infections, imminent vesicoureteral reflux, stone formation, or bladder carcinoma, indwelling transurethral catheters be avoided whenever possible. Whenever a continuous flow system is necessary, a suprapubic fistula should be preferred. Use of 
closed systems and optimal hygiene is mandatory. In patients with persistent detrusor hyperreflexia, anticholinergic drugs may be added regularly. Use of silicone catheters with antireflux systems, avoidance of disconnections, and acidification of urine are all recommended. The value of bladder flushing and of treatment with lowdose antibiotics is uncertain [120].

Botulinum toxin type A injected into a spastic bladder sphincter muscle is a promising new treatment option (class III evidence [128], although larger studies are still ongoing. In patients with detrusor hyperreflexia, cystoscopic injection into the bladder wall led to improved bladder capacity and continence could be ameliorated, with these effects lasting for up to 9 months (class III evidence [129]). An open multicenter study in 231 patients with neurogenic detrusor hyperactivity showed a clear amelioration of bladder capacity, reflex volume, and average micturition pressure after injection of $300 \mathrm{MU}$ botulinum toxin type A (class III evidence [130]).

Neuromodulation and surgical procedures: Chronic S3 root stimulation using implantable electrodes may be promising in patients with hyperreflexive bladder who do not respond to any other treatment (class III evidence [131]). Nevertheless, this treatment should be restricted to very experienced and specialized centers. Other operations, e.g. sphincterotomies, stent implantations in patients with detrusor sphincter dyssynergia as well as autoaugmentation of the bladder are still under study and cannot generally be recommended; moreover, in MS the natural course of bladder dysfunction over longer time periods is often uncertain.

\section{Recommendations}

- Exclusion of bladder infection; treatment with appropriate antibiotics if infection is present.

- Evaluation with micturition diary, clinical examination, sonographic evaluation of residual volume and uroflowmetry in case of obstruction, creatinine; creatinine clearance and sonography of the abdomen if necessary (type B recommendation).

- Counselling for adequate fluid intake; information on incontinence devices, acidification of urine with methionine or cranberry extract (expert opinion).

- In uncomplicated urgency, low disability status and with absent urological side effects pelvic floor training, toilet training in patients with at least partially maintained sphincter control are useful (type B recommendation); drugs to diminish detrusor hyperactivity include trospium chloride or tolterodine, oxybutynin, propiverine, solifenacin, darifenacin (type A recommendation); electrostimulation at $\mathrm{S} 3$ root level (type $\mathrm{C}$ recommendation).

Symptomatic Treatment of Multiple Sclerosis
- If obstruction with or without urgency is present, urodynamometry and initiation of treatment is recommended in cooperation with an urologist. In most cases: treatment with anticholinergic drugs combined with intermittent sterile catheterization may be of some value (expert opinion).

- In detrusor hyperreflexia and pronounced adverse effects of oral anticholinergic drugs intravesical instillation of anticholinergics or injection of botulinum toxin type A (type $\mathrm{C}$ recommendation) is a treatment option.

- Recurrent bladder infections: Counselling on specific causes, optimization of symptomatic treatment, methionine, in severe cases combined with methenamine (expert opinion); avoidance of chronic antibiotic treatment (expert opinion).

- Severe nocturia: desmopressin $20 \mu \mathrm{g}$ intranasally (type B recommendation).

- Long-term catheterization and surgery is recommended only in treatment-resistant cases because of its irreversibility, late complications and unpredictable course of the disease (type $\mathrm{C}$ recommendation).

\section{Neurogenic Bowel Dysfunction}

Disturbances of bowel function like constipation and/ or incontinence will occur in about $70 \%$ of MS patients. With respect to the frequency of constipation in healthy people, a causal connection MS is often questionable. On the other hand, negative sequels on some MS symptoms such as NBD and spasticity are well known. The diagnosis is made by the patients' descriptions and clinical examination. Other gastrointestinal diseases should be excluded. If constipation occurs, it is of great importance to differentiate between reduced bowel motility and disturbance of rectum and bowel emptying. In some cases, estimation of the colon transit time after oral administration of X-ray-positive markers may be helpful.

Goals of treatment are to normalize the frequency of bowel emptying, to achieve continence and to prevent (sub)ileus and pressure sores.

\section{Specific Treatment}

\section{Physiotherapy, Aids, Medical Treatment}

In a small open study, biofeedback seemed to be effective in less disabled patients [132]. The benefit of pelvic floor training has so far never been elucidated [133]. Fecal incontinence in women with weak pelvic floor muscles may be ameliorated partially by electrical stimulation 
[134]. There are treatment trials providing sufficient data on the use of laxatives, drugs augmenting bowel motility, and botulinum toxin A $[132,135]$. The established guidelines are likely to be applicable also in MS patients.

\section{Recommendations}

In case of prevailing constipation (expert opinion)

- Sufficient fluid intake (1.5-2 1/day), nutrition rich in dietary fiber.

- Physiotherapy (standing devices, motor-driven bicycles, colon massage).

- Pelvic floor training for relaxation of sphincter muscles, biofeedback.

- In case of hardened feces lactulose or macrogol is recommended except if fecal incontinence is also present.

- Facilitation of rectal emptying by glycerin suppositories or rectal filling with fluids.

- In single cases: targeted utilization of 'reflexive emptying' (rectal emptying simultaneously with filled bladder, use of perianal trigger points, avoidance of crude sphincter extension).

- Avoidance of anticholinergic and antispastic drugs whenever possible.

- In case of painful sphincter spasticity or paradoxical sphincter/ puborectal contractions injection of low-dose botulinum toxin type A (e.g. 50-100 MIU Dysport).

- Bowel motility augmenting drugs like metoclopramide and domperidone are of questionable efficacy.

In case of prevailing fecal incontinence (expert opinion)

- Regular bowel emptying every 3rd to 4 th day.

- Massive bowel emptying in case of pseudodiarrhea or 'overflow incontinence'.

- In women with insufficient pelvic floor muscles but partially maintained sphincter control use of pelvic floor training, combination with intra-anal electrical stimulation is possible.

- Electromyography in patients with flaccid sphincter to rule out a peripheral neurogenic lesion.

- Adequate aids, e.g. fitted intra-anal tampons especially in patients with maintained walking ability.

- Meticulous skin care, prevention of pressure sores.

\section{Sexual Dysfunction}

Sexual dysfunctions do not only represent a problem of the individual patient but may also lead to conflicts within the partnership. Female patients often complain of reduced libido and lack of orgasm due to diminished genital sensitivity or dyspareunia. Males predominantly suffer from erectile dysfunction (ED) and, less frequently, early or failing ejaculation. Moreover, spasticity and muscular weakness will complicate sexual intercourse in both genders.

Primary sexual dysfunctions are directly caused by MS-related demyelination whereas secondary sexual dysfunctions are the consequences of specific MS symptoms like spasticity, fatigue, or bladder dysfunction. Tertiary sexual dysfunctions comprise the manifold psychological reactions due to MS-related disabilities. Nevertheless, not every relapse or worsening of MS will affect sexual life of the patient and her/his partner [136].

During the course of MS, sexual dysfunction will eventually occur in up to $80 \%$ of patients but is probably rare within the early years of the disease. Men are affected more frequently than women (75 vs. 50\%). Sexual dysfunction is usually combined with bladder dysfunction.

As patients often do not directly complain about sexual dysfunction, they should be asked for during the consultation. The goal of treatment is to normalize sexual activities of the MS patient and her/his partner as far as possible.

\section{Specific Treatment}

Before treatment a complete neurologic and sexualityrelated history, neurologic examination and, in some cases, neurophysiologic studies, e.g. pudendus-SSEP, are necessary. Patients should be asked for drugs which may interfere with sexual function, e.g. antidepressants, benzodiazepines, neuroleptics, antiepileptic drugs, clonidine, or $\beta$-blockers. MS symptoms which may impair sexual intercourse like adductor spasticity or bladder infection or incontinence should be treated appropriately. Conflicts within the partnership prompt counselling by an experienced specialist and may profit from psychotherapy [137].

\section{Drug Treatment}

The phosphodiesterase-5 inhibitor sildenafil is now the most intensively studied drug for ED. 25-100 mg of sildenafil should be taken orally $1 \mathrm{~h}$ before sexual intercourse and will result in a significant improvement in terms of achieving as well as maintaining erections. Adverse side effects like headaches, flushing, rhinitis, dizziness, or dyspepsia were all rare and did not lead to discontinuation of treatment (class I evidence [138]). 
Contraindications like coronary heart disease, recent myocardial infarcts and stroke as well as co-medication with nitrates and molsidomine have to be carefully excluded since they may be life-threatening if sildenafil is used simultaneously. In the future, the newer phosphodiesterase-5 inhibitors vardenafil and tadalafil may offer some advantages with respect of duration of effect and adverse events.

Especially in patients with cardiac dysfunction in which sildenafil and analogues are contraindicated, sublingual apomorphine may be an alternative. This drug can be used 'on demand' since its effect will start about $20 \mathrm{~min}$ after ingestion. Up to $6 \mathrm{mg}$ will lead to a significant better erection compared to placebo (class II evidence [139]). Apomorphine may be less effective compared to sildenafil and its adverse effects, especially nausea and fatigue, will often limit its use. In patients suffering from psychogenic ED, yohimbine may ameliorate erection [140].

In female patients with reduced lubrication and resulting dyspareunia, treatment with tibolone, estrogen-containing unguents, or commercially available lubricant creams can be recommended (class III evidence [141, 142]). After treatment with sildenafil a positive effect on lubrication could be demonstrated in only a few female MS patients (class I evidence [143]).

\section{Invasive and Surgical Treatments, Aids}

After the introduction of sildefanil and analogues, invasive procedures can often be avoided. No formal comparative studies are available. Injection of prostaglandins into the cavernous body of the penis has proven to be an effective treatment (alprostadil 2.5-20 $\mu \mathrm{g}$ into the cavernous body [144]; class II evidence [145]). Transurethral application is also possible (class I evidence [146]). Patients have to be carefully instructed of some adverse effects like penile pain, dizziness as well as a long-lasting and sometimes painful erection. Treatment should be started using low doses of alprostadil. Nevertheless, after the introduction of phosphodiesterase- 5 inhibitors, alprostadil is only a second-line drug for treatment of ED.

If patients tend to avoid drug treatment for ED, vacuum pumps may be considered (class III evidence [147]). Penis prostheses offer a further treatment option [148].

\section{Recommendations}

- Discontinuation of drugs which can provoke or enhance ED; treatment of bladder infections and focal spasticity (expert opinion).

- Diagnosis and treatment of existing conflicts of partnership (expert opinion).

- In ED treatment with sildenafil (type A recommendation). If contraindications or intolerance against sildenafil are present, treatment with sublingual apomorphine may be initiated (type $B$ recommendation); intracavernous or transurethral alprostadil if appropriate (type B recommendations).

- Hormone preparations like tibolone in female patients with loss of libido or dyspareunia (type B recommendation).

\section{Ataxia and Tremor}

During the course of their disease, about $80 \%$ of MS patients suffer from disabling ataxia which often comprises cerebellar, spinal or sensory ataxic symptoms. Truncal as well as limb ataxia of upper extremities with distal intention tremor represent one of the most disabling MS symptoms especially when combined with postural tremor and dysmetria. The degree of ataxic symptoms is often fluctuating depending on the current physical strength or psychological situation of the patients.

Quantification of ataxia may be mostly achieved using clinical and activity-of-daily-living (ADL) scores [149, 150]. The goal of treatment is amelioration of ataxia, especially when severely interfering with daily activities as well as social or occupational life.

\section{Specific Treatment}

The cornerstones of treatment are physiotherapy and occupational therapy. Drug treatment which can only reduce the tremor component, is usually less helpful. Surgical procedures only play a limited role.

\section{Physiotherapy, Occupational Therapy}

They should be embedded within an overall concept implying tonus regulation, reduction of muscular fixations, stabilization of the trunk, training of sensory skills, coordination of movements, ataxia-inhibiting techniques as well as supply with aids. Treatment using large supporting surfaces should slowly be reduced. Training should prefer methods with special respect to daily life 
requirements. Moreover, appropriate aids should be used, e.g. cutlery with thickened grips and enlarged supporting areas. In patients with arm pareses or truncal instability, proprioceptive facilitation techniques may be used for the amelioration of muscle tone.

The use of wrist hefts in patients with postural tremor was shown to be ineffective [151] and, moreover, may even cause enhancement and fixation of elevated muscular tone. Whenever possible, patients should be trained to reduce muscular fixations using specific relaxation techniques.

A significant reduction of intention tremor may be achieved by short-term (1 min) local application of ice (class III evidence [149]). In another comparative study using cooling cuffs (skin temperature 18 vs. $25^{\circ} \mathrm{C}$ ) a temperature-correlated effect on postural tremor could be demonstrated (class III evidence [152]). Local cooling may be used by the patients themselves whenever necessary, e.g. before meals, intermittent self-catheterization, or PC work.

\section{Drug Treatment}

In individual cases, antiepileptic and other centrally acting drugs as well as $\beta$-blockers can be used additionally in patients with severe intention tremor.

A clear benefit of $\beta$-blockers could only be demonstrated in essential tremor whereas propranolol was not effective in patients with cerebellar tremor (class III evidence [153]). Besides this, some patients apparently may profit from treatment with $\beta$-blockers since these drugs will mitigate psychic agitation and thus reduce tremor.

Antiepileptics. Primidone may be effective in essential tremor but sedative side effects limit its use. Gabapentin will ameliorate essential and orthostatic tremor and carbamazepine (class III evidence [154]) as well as topiramate (class III evidence [155]) may positively influence cerebellar tremor.

Other Drugs. Clonazepam (3-6 mg/day) may be of some benefit in cerebellar tremor, too [156]. The effect of oxitriptan (5-hydroxytryptophan) on ataxia of the trunk and legs usually occurs only after treatment with $3 \times$ $300 \mathrm{mg} /$ day over about 6 weeks (class III evidence [157]). Up to now, ondansetron, a 5-hydroxytryptophan-(HT-3) antagonist, showed conflicting results. Using $8 \mathrm{mg}$ of oral ondansetron, no significant reduction of cerebellar symptoms could be demonstrated (class III evidence [158]; class III evidence [159]), whereas intravenous ondansetron $(8 \mathrm{mg} /$ day) caused a clear short-lasting amelioration of writing ataxia and of the patients' subjective impression (class III evidence [160]).
Isoniazid has been used in patients with cerebellar tremor with conflicting results (class III evidence [153, 161]). Adverse effects may limit treatment. Physostigmine has no significant effect on cerebellar tremor [162, 163].

Cannabinoids as well as alcohol may reduce ataxic symptoms [153, 164]. Nevertheless, treatment with these substances cannot be recommended due to insufficient data and adverse effects, especially the risk of addiction.

\section{Surgical Treatment}

With stereotactic operations, e.g. VIM thalamotomy and VIM (deep brain) stimulation, reduction of tremor could be demonstrated though VIM thalamotomy is not as effective in MS patients as in those with Parkinson's disease. Chronic VIM stimulation will produce better results but stimulation parameters probably have to be optimized repeatedly. In some smaller studies and case series, amelioration of tremor could be achieved in $87.7 \%$ and of activities of daily life in $76 \%$ of operated patients [165]. Simultaneously the level of disability and SF-36 subscales remained largely unchanged (class III evidence $[166,167])$. Fortunately, peri- and postoperative complications are rare. Best treatment results may be achieved in patients with stable tremor, e.g. marked axial and proximal arm tremor, and trunk ataxia [168]. If stereotactic treatment is considered, the patients' disease course should be stabilized by effective immunotherapy for at least 1 year (expert opinion).

\section{Recommendations}

- Regular physiotherapy and occupational therapy, cooling (expert opinion).

- In patients with predominant tremor: additional drug treatment (monotherapy) with a $\beta$-blocker (rapid assessment of efficacy) and, if not successful, monotherapy with carbamazepine, primidone or clonazepam. If escalation is necessary, combination therapy with a $\beta$-blocker and an antiepileptic drug (type $\mathrm{U}$ recommendation). Efficacy of these drugs is often limited by their extensive adverse effects.

- If tremor is unresponsive to combination therapy: oxitriptan (type $\mathrm{U}$ recommendation).

- Only in patients with considerable tremor unresponsive to drug treatment or with severe side effects electrical stimulation of the thalamus should be considered (type $\mathrm{C}$ recommendation). 


\section{Cognitive Dysfunction}

Dysfunctions of cognitive skills of some degree may affect up to $70 \%$ of patients with long-standing MS. Impairments mostly include attentional domains, memory, executive functions, in particular 'multitasking' skills, and constructive visual skills, whereas implicit function and speech are rarely disturbed. The patients' perception of his/her cognitive dysfunction is often inadequate or even missing [169].

Diagnostic procedures should include a detailed history of the patients' capabilities in daily living and in his/ her occupation followed by standardized testing of the different cognitive functions.

\section{Specific Treatment}

The treatment is aimed at the training of preserved functions and at strategies to compensate existing deficits. It is necessary to focus training on specifically disturbed cognitive functions. In many patients, several cognitive categories and affective disturbances have to be treated simultaneously.

\section{Attention Training}

Nowadays, PC-based techniques are used to treat permanent and selective alertness or activation of alertness (class III evidence [170-172]). Even the ability to cope with distracting stimuli may be ameliorated. Repeated treatment will result in better performance.

\section{Memory Training}

Pure repetitive learning is hardly effective. In less severely affected patients, training of memory strategies may be helpful, whereas severely affected patients usually need memory aids like notebooks and reminders, e.g. 'NeuroPage' (class II evidence [173], class III evidence [174], class III evidence [175]). Training and performance control should be done several times a week. Structured memory training in MS patients with moderate to severe learning impairments may lead to improved memory performance (class I evidence [176]). Simple tasks such as crossword riddles, puzzles or other games training memory skills may turn out to be of some benefit, too.

Combination of memory training with relaxation techniques, treatment of simultaneous depression, counselling and compensational strategies is helpful. Moreover, family members, other relatives or near friends may be included into the treatment process which again has to be of adequate duration and regularity (class I evidence [177-179]).

\section{Drug Treatment}

So far, cholinesterase inhibitors like physostigmine and donepezil and, in addition, 4-AP and amantadine have been studied with respect to their effect on cognitive dysfunction. Moreover, there are some data suggesting a reduction of cognitive decline during immunomodulatory treatment of MS with $\beta$-interferons and GLAT.

Donepezil, which is used for the treatment of Alzheimer-type dementia, may ameliorate memory functions, especially verbal learning and memory, but also of alertness and executive functions (class I evidence, $10 \mathrm{mg} /$ day [180], class III evidence [181]).

In severely disabled MS patients, the amplitudes of cognitive evoked potentials could be improved with amantadine but reaction time measurements did not [182]; the clinical significance of these findings has to be determined [183].

$\beta$-Interferons, GLAT: During treatment with $\beta$-interferon- $1 \mathrm{~b}$ the visuospatial performance in treated patients was stable compared to deterioration of this task in patients on placebo (class II evidence [184]). Similar results have been achieved during $\beta$-interferon- $1 b$ treatment with respect to alertness, concentration, visual learning and recognition (class II evidence [185]). On the contrary, another study using the same interferon in patients with relapsing-remitting MS failed to show any improvement of verbal memory (class III evidence [186]).

In a post-hoc evaluation of a study using $\beta$-interferon1a, significant differences with respect to information processing, memory, visuospatial and executive functions could be demonstrated after 2 years of treatment compared to placebo (class II evidence [187]).

Studies using GLAT [188] or methotrexate [189] could not detect any improvement or even stabilization of cognitive dysfunction.

\section{Recommendations}

- Training should be aimed specifically at the disturbed cognitive function(s). High-frequency treatment is mandatory (type B recommendation).

- Complex neuropsychological treatment is preferable, e.g. treatment of simultaneous depression, relaxation techniques, counselling within multimodal rehabilitation (type B recommendation).

- With immunomodulatory treatment cognitive decline may be delayed. 
Table 1. Paroxysmal symptoms in multiple sclerosis

- Trigeminal, glossopharyngeal and other neuralgias (including MS-associated (pseudo)radicular pain)

- Sensory symptoms: paresthesias, dysesthesias, pruritus, Lhermitte's sign

- Paroxysmal ataxia and dysarthria

- Dyskinesias: paroxysmal dystonia (formerly: tonic brainstem seizures), facial hemispasm, tremor, akinesia (loss of muscle tone, kinesiogenic choreoathetosis

- Facial myokymia

- Myoclonus, e.g. palatomyoclonus, singultus (hiccup)

- Vertigo, nausea/vomiting, cough

- Blurred vision, oscillopsia, convergence spasm, spasm of m. rectus superior/levator palpebrae, ocular flutter, ocular tilt

- Uhthoff's phenomenon

\section{Depression}

Depressive syndromes occur in about $50 \%$ of MS patients [190] though episodic fluctuations of depressive mood (International Classification of Disease-10, ICD10: F32, F33) or difficult coping have to be distinguished from long-term depressive states (ICD-10: F34) and 'organic' major depression (ICD-10: F06.32). Even bipolar affective psychoses in MS patients can be seen twice as much as in normal population [191]. Diagnosis will be made according to ICD-10 criteria mentioned above. Goals of treatment are the reduction of depressive mood by proper guidance and drug treatment when needed as well as prevention of suicide.

\section{Specific Treatment}

\section{Counselling}

As depression is often masked by physical symptoms (fatigue, exhaustion, cognitive problems) it should actively be searched for during the consultation. Whenever depression is obvious, a psychiatric examination should precede counselling through the local MS society chapters or by friends and family (class II evidence [192]).

\section{Psychotherapy}

Several studies demonstrate the efficacy of psychotherapy for depression in MS patients (class II evidence $[179,193,194]$, class III evidence [195]). Mainly cognitive behavioral therapy has been applied, though no preference of a specific psychotherapeutic technique has been worked out.

\section{Drug Treatment}

A Cochrane review emphasizes the efficacy of tricyclic antidepressants as well as of SSRIs in depressive patients with other medical illness [196]. Treatment with desipramine combined with psychotherapy (class II evidence [191]), with sertraline and psychotherapy (class II evidence [194]), and with the monoaminoxidase (MAO) A inhibitor moclobemide (class III evidence [197]) are effective. In the individual patient the potential adverse effects may help to select the drug for treatment.

Recommendations

- Counselling as prophylactic and complementary treatment (type B recommendation).

- Drug treatment with tricyclic antidepressants, serotonin reuptake inhibitors, noradrenalin reuptake inhibitors, MAO A inhibitors (type A recommendation).

- Structured psychotherapy using accepted techniques, e.g. cognitive behavioral therapy (type A recommendation).

\section{Paroxysmal Symptoms}

About $10-20 \%$ of MS patients suffer from paroxysmal symptoms like trigeminal neuralgia (TN) and several other paroxysmal painful, sensory and - more rarely motor symptoms (table 1). These are very short stereotype symptoms lasting from seconds to several minutes occurring spontaneously or triggered by sensory stimulants, movement, change of body position or hyperventilation. They may appear up to several hundred times a day.

The diagnosis is made on clinical findings and should be completed by the documentation of frequency, localization, quality and intensity, duration, triggers and accompanying symptoms, e.g. using a diary.

\section{Specific Treatment}

Patients should be instructed to avoid triggers like specific movements, heat or sensory stimuli. Physiotherapy is not effective. Drug treatment mainly consists of antiepileptic drugs, especially carbamazepine, and more recently, gabapentin. If paroxysmal symptoms occur during a relapse of MS, high-dose steroid therapy should be introduced according to established guidelines [1]. With the exception of TN treatment, high-quality studies are lacking. 


\section{Trigeminal Neuralgia}

\section{Drug Treatment}

MS-associated TN is treated as any other type of TN. According to several controlled studies, carbamazepine is still the first-line drug [198]. Nevertheless, even in sufficient dosage carbamazepine may cause a paradoxic increase of some MS symptoms in single patients [199, 200]). Phenytoin, baclofen (class III evidence [201]), lamotrigine (up to $400 \mathrm{mg} /$ day, class II evidence [202]), gabapentin (up to $1,600 \mathrm{mg}$, class III evidence $[203,204]$ ), topiramate (up to $300 \mathrm{mg} /$ day, class III evidence [205]), oxcarbazepine and valproate are second-line drugs. Up to now no comparative drug trials have been published.

Especially in emergency situations the efficacy of phenytoin has been proven since the drug can be injected intravenously. The efficacy of lamotrigine could be demonstrated even when combined with carbamazepine [206]. Unfortunately, the dose of lamotrigine has to be increased very slowly precluding its rapid action. The prostaglandin $\mathrm{E}_{1}$ analogue misoprostol may offer another treatment option for TN in MS patients $(600 \mu \mathrm{g} /$ day, class III evidence [207]).

\section{Surgical Treatment}

Surgical interventions, like thermocoagulation and glycerol instillation into the cavum Meckeli are widely accepted as second-line therapies for TN [208]. Microvascular decompression of the trigeminal nerve has been performed successfully even in single MS patients (class III evidence [209]), but in some of them complete pain relief could only be achieved after partial rhizotomy. On the contrary, radiosurgery is a minimal invasive procedure and causes hypo- and dysesthesias in only $10 \%$ of patients. $75 \%$ of patients will remain free of pain even after 3 years. Unfortunately there are no data on long-term success compared to other surgical techniques (class III evidence [210]). Moreover, high-quality studies examining the efficacy of these surgical techniques in MS patients are still lacking. In MS patients with TN, the achievement of complete pain relief may require a higher number of surgical interventions to result in permanent relief when compared to TN of other origin [211].

\section{Other Paroxysmal Symptoms}

Paroxysmal paresthesias and pain may occur spontaneously or are triggered by movement or posture within one part of an extremity. They will usually last up to several minutes.

Carbamazepine is still the most important and most effective drug for the treatment of these paroxysmal symptoms and daily doses of 100-300 mg may lead to complete relief of the symptoms treated. Gabapentin (up to $1,200 \mathrm{mg} /$ day, class III evidence [212]), lamotrigine (up to $400 \mathrm{mg}$ /day, class III evidence [213]), phenytoin or valproate have as well been used successfully. Even with clonazepam and the sodium channel blocking agents lidocaine and mexiletine, several motor and sensory paroxysmal symptoms could be sufficiently reduced [214, 215].

Patients with Uhthoff's phenomenon should be told to avoid heat and to use cooling techniques. Moreover, 4-AP may be of some value [53]. The treatment of choice in the rare facial hemispasm is the application of botulinum toxin A once the hemispasm becomes disabling [216].

Recommendations

- In most cases, paroxysmal symptoms respond to treatment with carbamazepine (type A recommendation). If paroxysmal symptoms newly occur with an acute relapse, a high-dose steroid treatment according to established guidelines should be introduced (expert opinion).

- If carbamazepine is not sufficient or causes worsening of other MS symptoms: treatment with another antiepileptic agent like lamotrigine, gabapentin (or oxcarbazepine in patients with $\mathrm{TN}$ ), or phenytoin, topiramate or valproate when appropriate can be tried (type $\mathrm{U}$ recommendation).

- For treatment of paroxysmal motor symptoms (spasm or myoclonus) treatment with clonazepam (type U recommendation).

- In patients with drug-resistant TN: consider thermocoagulation or instillation of glycerol into the cavum Meckeli, alternatively microvascular decompression or radiosurgery may be recommended (type $\mathrm{C}$ recommendation).

\section{Oculomotor Symptoms}

During the course of the disease about $30-50 \%$ of MS patients will suffer from oculomotor symptoms and in about 13\% they may be part of the first relapse. The most important symptoms are internuclear ophthalmoplegia and different forms of nystagmus like upbeat/downbeat 
nystagmus or, less commonly, pendular nystagmus. It enhances during fixation and results in oscillopsia and blurred vision.

\section{Specific Treatment}

Oculomotor symptoms occurring during a relapse should be treated with high-dose intravenous methylprednisolone. An eye patch may be helpful during the acute phase to avoid double vision.

For drug treatment of pendular nystagmus gabapentin (900-1,200 mg/day, class II evidence [217], class III evidence [218]) or memantine (40-60 mg/day, class III evidence [219]) should be used. Scopolamine adhesives, vigabatrin or baclofen are not effective.

Baclofen $(3 \times 5 \mathrm{mg} /$ day $)$ may reduce upbeat/downbeat nystagmus [220]. A single dose of 3,4-DAP (20 mg) will ameliorate downbeat nystagmus of different etiologies (class I evidence [221]). There are no data concerning 3,4-DAP treatment in MS patients with downbeat nystagmus. 4-AP has been successfully used so far in 2 patients (class III evidence [222, 223]).

Patients suffering from internuclear ophthalmoplegia rarely complain of blurred vision despite impressive motility defects, so that treatment is not necessary.

\section{Recommendations}

- Treatment with gabapentin or memantine in pendular nystagmus (type B recommendation).

- For upbeat/downbeat nystagmus baclofen is the drug of first choice (type A recommendation), for downbeat nystagmus 3,4-DAP may be used (type B recommendation).

- In internuclear ophthalmoplegia drug treatment is rarely needed.

\section{Dysarthria and Dysphonia}

Dysarthria, a dysfunction of articulation, and dysphonia, a dysfunction of phonation, are each a component of dysarthrophonia indicating a profound incoordination of tongue, glottis, larynx and respiratory muscle movements. Estimates of its frequency range between 20 and $62 \%$, depending on the definition of abnormality. Among their many different forms [224, 225], spastic and ataxic dysarthria are most often present in MS patients. Dysarthrophonia can be augmented by early fatigue resulting in progressive dysfunction over a longer conversation or during a speech.

Degree of dysarthria correlates with the severity of neurological impairment and the duration of disease [225]. Important features are a dysfunction of loudness control (77\%), harsh voice quality (72\%), imprecise articulation (46\%), impaired emphasis (39\%), impaired pitch control (37\%), decreased vital capacity (35\%) as well as hypernasality (24\%) [226]. Dysarthria and dysphonia both impair communicative and psychosocial abilities by restricting the patients' participation in professional and social life.

Severity of dysarthria may be measured by several scales, e.g. the NTID National Technical Institute for the Deaf (NTID) - scale of understandability [227], the Frenchay Dysarthria Examination [228], the Voice Handicap Index (VHI [229]) or the Voice-Related Quality of Life Index (V-RQOL [230]). Goals of treatment are the restoration of lost speech functions and thus of the ability of unimpaired communication.

\section{Specific Treatment}

Speech therapy is indicated whenever dysarthria or dysphonia interfere with correct transmittal of verbal messages; when speech and voice are not longer sufficient to facilitate everyday communication; when impaired speech, voice and communication reduce quality of life through social isolation and imminent loss of occupation, and when the patient and his relatives are increasingly stressed by dysarthria and dysphonia.

Treatment should be performed by a team comprising a neurologist, an otorhinolaryngologist and a speech therapist. Three general areas of dysfunction may underlie dysarthria/dysphonia: decreased respiratory output, decreased respiratory/phonatory coordination and control, and reduced phonatory function [231]. Techniques to modify speech behavior, drug treatment and communication aids are all important components of therapy. Unfortunately, not every MS patient is suited for treatment since rapid disease progression, cognitive and behavioral impairment and, over and above, reduced motivation will affect its success.

\section{Behavioral Techniques}

Behavioral techniques include speech tasks (phonetic, linguistic, and pragmatic methods as well as non-speech tasks (postural adjustment, breathing strategies, feedback methods and neurophysiological concepts, e.g. Bo- 
bath technique, proprioceptive neuromuscular facilitation). Recently, an algorithm on existing treatment options has been developed under the auspices of the Academy of Neurologic Communication Disorders and Sciences (ANCDS) [225, 231]. Treatment consists of:

- Training of tactile and auditive perception on speechrelated muscular motions.

- Aware control of usually automated processes.

- Inhibition of abnormal posture and movement.

- Measures to normalize muscle tone, e.g. enhancement of flaccid muscle tone or its reduction in spastic elevation of tone.

- Repetitive training of physiologic movements.

- Biofeedback.

In spastic and ataxic dysarthria as the most common speech disorders, control of speech rate, voice emphasis and phrase shift, reduction of phrase length and increase of voice power are the mainstays of treatment [232, 233]. Controlled studies are still lacking for MS. In patients suffering from Parkinson's disease, a beneficial effect of this treatment on loudness and dysarthria could be demonstrated but no superiority of a special technique [234236]. In most of the Parkinson patients with hypokinetic dysarthria the 'Lee Silverman Voice Treatment' (LSVT) had been used which also may be effective in MS patients [237]. In an evidence-based evaluation it could be demonstrated that biofeedback can be effective in changing physiologic variables. However, the relationship between these changes and speech production or communicative participation has yet to be clearly established [225].

\section{Prosthetic and Other Technical Aids}

In patients with nasal speech due to impaired function of the soft palatine the velum can be elevated by a velum prosthesis fixated to the teeth to ameliorate hypernasality [238].

Technical aids like a pacing board, graduated sticks or a metronome can help to control speech velocity whereas a delayed auditory feedback unit may reduce it. 'White' (background) noise presented via headphones often leads to a spontaneous increase of loudness (Lombard effect). Alternatively, electronical voice amplifiers may be used. As with any speech behavioral technique, the effectiveness of these devices cannot be estimated sufficiently due to the small number of patients published. Nevertheless, in an ANCDS review it was stated that these devices 'may improve speech loudness and, in most cases, intelligibility of speech in individuals with hypokinetic dysarthria' [225].

\section{Drug Treatment}

There is no recommendation for the use of drugs in dysarthria. In patients with adductor spasmodic dysphonia, injections of botulinum toxin A may result in substantial improvement in several patients whereas the improvement of abductor spasmodic dysphonia seems to be less clear [239]. Additional training may enhance the positive effect of botulinum toxin A treatment [239, 240]. In MS patients there is very limited experience [241].

\section{Surgical Treatment}

For constriction of the glottis in patients with vocal chord paresis, injections of teflon or collagen fluids were reported. Phonosurgical operations may ameliorate position and tone of the vocal folds [242] and velopharyngeal surgery can be considered if a velum prosthesis is not effective [243]. None of these procedures has been formally tested in MS patients.

\section{Speaker Strategies, Augmentative and Alternative \\ Communication Techniques}

When verbal communication is reduced to less than $50 \%$ of intelligibility, special strategies and aids should be used. Speech supplementation strategies provide additional information to the speech signal. They include alphabet supplementation in which the speaker indicates the first letter of the word spoken on an alphabet board, topic supplementation and gesture accompanying speech. It is suggested that listener training should be included into the therapeutic setting [244]. A variety of electronic communication devices have been developed including electronic typewriters and minicomputers with synthetic speech processing that supplement or replace impaired verbal communication. Communication aids may be characteror symbol-oriented. Using laser or infrared controls for transmission, these aids may be utilized even by patients suffering from severe motor impairment [233, 245].

Before these more demanding aids are introduced to MS patients, their cognitive, motor, visual and acoustic skills should first be checked and the acceptance of the patients and his interlocutor be considered [244]. A longer learning period is to be expected in an advanced MS patient than in an otherwise healthy language skills disorder.

Treatment recommendations are based only on limited clinical experience from small studies concerning therapy of dysarthria in other diseases, and on expert opinion and plausibility of methods investigated [246]. 
Recommendations

- Speech therapy in patients with relevant dysarthria (expert opinion).

- Co-treatment of associated symptoms, e.g. fatigue, spasticity, tremor (expert opinion).

- Speech supplementation techniques und communication aids in patients with severely impaired understandability despite speech therapy (expert opinion).

\section{Dysphagia}

Estimates on the frequency of dysphagia vary between 24 and 55\% depending on the intensity of diagnostic procedures and disease progression. Severely impaired patients (EDSS 8-9) may be affected even more frequently. Occasionally, patients with an EDSS up to 2.5 may present with dysphagia but less commonly they complain about discomfort.

Difficulties in swallowing will provoke recurrent cough and increased sialorrhea. Moreover, quality of life is often markedly reduced due to impaired pleasure of drinking and eating. In severely afflicted patients, dehydration, malnutrition, and (silent) aspiration of food and/ or fluids with subsequent aspiration pneumonia may cause even life-threatening problems.

Patients with impaired swallowing should undergo a careful assessment including a detailed history related to specific symptoms of dysphagia, a neurological and otorhinolaryngological examination and a functional swallowing test. When in doubt, a videofluorographic swallowing study (VFSS) and/or transnasal fiberoptic endoscopic examination of swallowing (FEES) may help in establishing a diagnosis.

The severity of dysphagia can be estimated according to clinical and radiological findings. In the near future the newly developed SWAL-QOL and SWAL-CARE outcome tools may be used additionally, which consider patients' perspectives and quality of life. They have also been validated in MS patients [247]. Goals of treatment are the avoidance of insufficient fluid and food intake, avoidance of aspiration and secondary pneumonia as well as amelioration of quality of life.

\section{Specific Treatment}

Exsiccosis, malnutrition and proven aspiration (by observing recurrent aspiration pneumonia) are urgent indications for active treatment of dysphagia. Treatment consists of functional therapy including swallowing therapy, drug treatment and other palliative measures. A qualified speech-language pathologist is of special importance. There are no data from controlled clinical studies in MS patients with dysphagia. The evidence of a treatment effect is derived from few controlled studies in other neurologic diseases, from clinical experience, expert opinion and plausibility of treatment methods.

\section{Functional Treatment (Swallowing Therapy)}

Functional treatment comprises

- restorative (facilitation or inhibition of muscular function),

- compensatory (postural changes and swallowing techniques/maneuvers) and

- adaptive methods (pureed food, mechanical altered diet, thickened or carbonated liquids, acidification of food, eating and drinking aids, counselling on eating behavior).

These methods are often used in combination [248]. In a comprehensive technical review of the American Gastroenterological Association, swallowing therapy was given a type $\mathrm{C}$ recommendation according to limited evidence of published studies [249]. In a Cochrane review on interventions for dysphagia in acute stroke a benefit of swallowing therapy could not be shown. This might be due to the small numbers of patients investigated [250]. Nevertheless, in an evidence-based systematic review of the Agency for Health Care Policy and Research (AHCPR), dramatic reductions in the occurrence of pneumonia were observed when a systematic program of diagnosis and treatment of dysphagia was implemented in an acute stroke management plan [251]. Further reports have shown efficacy of swallowing therapy or of single methods used in swallowing therapy on clinical relevant endpoints such as restoration of oral intake (class III evidence [252, 253]) or swallow scores which reflect activation limitations (class II evidence [254, 255], class III evidence [256, 257]). Only one single study exists on MS patients. It demonstrated that in mild and moderate dysphagia, aspiration observed by FEES could be avoided by swallowing therapy. This was not the case in severe dysphagia (class III evidence [258]). Recommendations on swallowing therapy in patients with MS are therefore based on expert opinion, plausibility of applied methods and therapeutic interventions in diseases other than MS [246, 259]. 


\section{Invasive and Surgical Treatment}

In some patients with pronounced and irreversible dysphagia, sufficient nutrition has to be maintained by a nasogastric/enteral tube or a percutaneous endoscopic gastrostomy (PEG), especially when a sufficient intake of food and fluids is impossible or severe aspiration has occurred despite conventional therapy [251, 260, 261].

Even if there are no sufficient data concerning MS patients, the results of nasoenteral or PEG feeding in other neurological disorders like amyotrophic lateral sclerosis (ALS) or stroke demonstrate its efficacy [250, 262, 263]. Nevertheless, application of this treatment for the individual patient has to be discussed responsibly [264]. Mild complications during insertion of a PEG may occur in $13-43 \%$ of patients, severe complications in $0.4-8.4 \%$, the mortality reaching $0-2 \%$ where the type of disease, age, other risk factors all seem to influence outcome [260]. In patients who required tube feeding within the first 2 or 3 weeks of stroke, fatality and poor outcome were significantly higher for those who were fed via PEG than via a nasogastric tube (class I evidence [265]). After 4 weeks, however, nutrition via a PEG proved to be more effective compared to a nasogastric tube, but was associated with more adverse effects (class I evidence [266]). Therefore in patients with transient dysphagia who require tube feeding and in whom a rapid improvement can be expected, e.g. after an acute relapse, a nasogastric tube may be applied.

Unfortunately, available data do not show that feeding tubes reduce the risk of pneumonia in patients with neurogenic dysphagia [251,267]. The offer for enteral tube feeding as prophylaxis against aspiration and pneumonia should be reserved to those patients who have developed recurrent pneumonia despite all efforts, whose coughing during meals is extremely uncomfortable and to the acutely ill with impaired consciousness [267]. In highly selected patients with recurrent pneumonia due to aspiration of saliva even a tracheotomy with a blocked cannula or other surgical interventions may be considered [249].

\section{Drug Treatment}

Pronounced hypersalivation may be attenuated using anticholinergic drugs [262] or by local injection of botulinum toxin A into the salivary glands as has been demonstrated in patients with ALS and Parkinson's disease [268-270]. Botulinum toxin A applied to the superior esophageal sphincter may reduce dysphagia due to an elevated sphincter tone [271].
Recommendations

- Functional swallowing treatment in patients with relevant dysphagia (type $\mathrm{C}$ recommendation).

- For patients who require tube feeding for $<3-4$ weeks, nasogastric tubes should be used, for longer periods feed via percutaneous endoscopic gastrostomy (PEG) (type B recommendation).

\section{Epileptic Seizures}

The prevalence of epileptic seizures in patients with clinically definite MS is estimated between 0.9 and $7.5 \%$ (normal adult population about 1\%). Seizures may occur with relapsing or with chronic progressive MS and, moreover, may be part of a relapse as well. Tonic-clonic and complex partial seizures are likely to be the most common types. Even a status epilepticus has been reported. In rare cases, seizures were thought to be the first clinical event.

\section{Specific Treatment}

To our knowledge, no studies have been performed dealing with treatment of epileptic seizures, especially in patients with MS. Therefore, they should be treated according to generally accepted guidelines concerning choice of drug and indication for monotherapy and combination of drugs, respectively. Following the first epileptic manifestation, treatment should be initiated if the seizure is likely due to an MS lesion (e.g. juxtacortical or cortical) due to the high risk of seizure recurrence [272]. Only if the seizure has been associated with a relapse, antiepileptic drug treatment may be deferred until after seizure recurrence. Termination of antiepileptic drug treatment has to be weighed against since the risk of injuries following a seizure is considerably high.

Recommendations

- Initiation of antiepileptic drug treatment after a first epileptic seizure with a likely association to appropriate lesion sites except it has been part of an acute relapse (expert opinion).

- Treatment regarding choice of drug, monotherapy or combination therapy according to existing guidelines. 


\section{References}

1 Multiple Sclerosis - Treatment Consensus Group (MSTCG): Escalating immunotherapy of multiple sclerosis. New aspects and practical application. J Neurol 2004;251: 1329-1339.

-2 Multiple Sklerose - Therapy Konsensus Gruppe (MSTKG): Immunomodulating escalating therapy of multiple sclerosis. Nervenarzt 1999;70:371-386.

$\checkmark 3$ Multiple Sklerose - Therapie Konsensus Gruppe (MSTKG): Immunomodulating escalating therapy of multiple sclerosis. 1st supplement December 2000. Nervenarzt 2001;72:150-157.

4 Multiple Sklerose - Therapie Konsensus Gruppe (MSTKG): Immunomodulating escalating therapy of multiple sclerosis - new aspects and practical implementation. Nervenarzt 2002;73:556-563.

$\checkmark 5$ Multiple Sklerose - Therapie Konsensus Gruppe (MSTKG): Symptomatic therapy of multiple sclerosis. Nervenarzt 2004;75(suppl 1):S2-S39.

6 European Multiple Sclerosis Platform: Recommendations on rehabilitation services for persons with multiple sclerosis in Europe. Brussels 2004.

7 Goodin DS, Frohman EM, Garmany GP Jr, Halper J, Likosky WH, Lublin FD, Silberberg DH, Stuart WH, van den Noort S: Disease modifying therapies in multiple sclerosis: report of the Therapeutics and Technology Assessment Subcommittee of the American Academy of Neurology and the MS Council for Clinical Practice Guidelines. Neurology 2000;58:169-178

$\checkmark 8$ Wiles CM, Newcombe RG, Fuller KJ, Shaw S, Furnival-Doran J, Pickersgill TP, Morgan A: Controlled randomised crossover trial of the effects of physiotherapy on mobility in chronic multiple sclerosis. J Neurol Neurosurg Psychiatry 2001;70:174-179.

-9 Paci M: Physiotherapy based on the Bobath concept for adults with post-stroke hemiplegia: a review of effectiveness studies. J Rehabil Med 2003;35:2-7.

-10 Nuyens GE, De Weerdt WJ, Spaepen AJ Jr, Kiekens C, Feys HM: Reduction of spastic hypertonia during repeated passive knee movements in stroke patients. Arch Phys Med Rehabil 2000;83:930-935.

-11 Laufens G, Poltz, W, Reimann, G, Schmiegelt, F, Stempski, S: Laufband- und Vojta-Physiotherapie an ausgewählten MS-Patienten Ein Vergleich der Soforteffekte. Phys Rehab Kur Med 1998;8:174-177.

-12 Buetefisch C, Hummelsheim H, Denzler P, Mauritz KH: Repetitive training of isolated movements improves the outcome of motor rehabilitation of the centrally paretic hand. J Neurol Sci 1995;130:59-68.
13 McPherson JJ, Becker AH, Franszczak N: Dynamic splint to reduce the passive component of hypertonicity. Arch Phys Med Rehabil 1985;66:249-252.

14 Mecomber SA, Herman RM: Effects of local hypothermia on reflex and voluntary activity. Phys Ther 1971;51:271-281.

15 Kesiktas N, Paker N, Erdogan N, Gulsen G, Bicki D, Yilmaz H: The use of hydrotherapy for the management of spasticity. Neurorehabil Neural Repair 2004;18:268-273.

16 Shakespeare D, Boggild M, Young C: AntiSpasticity Agents for Multiple Sclerosis (Cochrane Review). Cochrane Database Syst Rev 2003;(4):CD001332.

17 Nance PW, Sheremata WA, Lynch SG, Vollmer T, Hudson S, Francis GS, O'Connor P, Cohen JA, Schapiro RT, Whitham R, Mass MK, Lindsey JW, Shellenberger K: Relationship of the antispasticity effect of tizanidine to plasma concentration in patients with multiple sclerosis. Arch Neurol 1997;54:731736.

18 Smith C, Birnbaum G, Carter JL, Greenstein J, Lublin FD: Tizanidine treatment of spasticity caused by multiple sclerosis: results of a double-blind, placebo-controlled trial. US Tizanidine Study Group. Neurology 1994; 44:S34-S42.

19 Brar SP, Smith MB, Nelson LM, Franklin GM, Cobble ND: Evaluation of treatment protocols on minimal to moderate spasticity in multiple sclerosis. Arch Phys Med Rehabil 1991;72:186-189.

20 Orsnes GB, Sorensen PS, Larsen TK, Ravnborg M: Effect of baclofen on gait in spastic MS patients. Acta Neurol Scand 2000;101: 244-248.

21 Sawa GM, Paty DW: The use of baclofen in treatment of spasticity in multiple sclerosis. Can J Neurol Sci 1979;6:351-354.

22 Paisley S, Beard S, Hunn A, Wight J: Clinical effectiveness of oral treatments for spasticity in multiple sclerosis: a systematic review. Mult Scler 2002;8:319-329.

23 Cutter NC, Scott DD, Johnson JC, Whiteneck G: Gabapentin effect on spasticity in multiple sclerosis: a placebo-controlled, randomized trial. Arch Phys Med Rehabil 2000; 81:164-169.

-24 Mueller ME, Gruenthal M, Olson WL, Olson WH: Gabapentin for relief of upper motor neuron symptoms in multiple sclerosis. Arch Phys Med Rehabil 1997;78:521-524.

25 Zajicek J, Fox P, Sanders H, Wright D, Vickery J, Nunn A, Thompson A: Cannabinoids for treatment of spasticity and other symptoms related to multiple sclerosis (CAMS study): multicentre randomised placebocontrolled trial. Lancet 2003;362:15171526.
26 Killestein J, Hoogervorst EL, Reif M, Kalkers NF, van Loenen AC, Staats PG, Gorter RW, Uitdehaag BM, Polman CH: Safety, tolerability, and efficacy of orally administered cannabinoids in MS. Neurology 2002;58: 1404-1407.

-27 Vaney C, Heinzel-Gutenbrunner M, Jobin P, Tschopp F, Gattlen B, Hagen U, Schnelle M, Reif M: Efficacy, safety and tolerability of an orally administered cannabis extract in the treatment of spasticity in patients with multiple sclerosis: a randomized, double-blind, placebo-controlled, crossover study. Mult Scler 2004;10:417-424.

$>28$ Wade DT, Makela P, Robson P, House H, Bateman C: Do cannabis-based medicinal extracts have general or specific effects on symptoms in multiple sclerosis? A doubleblind, randomized, placebo-controlled study on 160 patients. Mult Scler 2004;10:434441.

29 Snow BJ, Tsui JK, Bhatt MH, Varelas M, Hashimoto SA, Calne DB: Treatment of spasticity with botulinum toxin: a doubleblind study. Ann Neurol 1990;28:512-515.

30 Hyman N, Barnes M, Bhakta B, Cozens A, Bakheit M, Kreczy-Kleedorfer B, Poewe W, Wissel J, Bain P, Glickman S, Sayer A, Richardson A, Dott C: Botulinum toxin (Dysport) treatment of hip adductor spasticity in multiple sclerosis: a prospective, randomised, double-blind, placebo-controlled, dose-ranging study. J Neurol Neurosurg Psychiatry 2000;68:707-712.

-31 Middel B, Kuipers-Upmeijer H, Bouma J, Staal M, Oenema D, Postma T, Terpstra S, Stewart R: Effect of intrathecal baclofen delivered by an implanted programmable pump on health-related quality of life in patients with severe spasticity. J Neurol Neurosurg Psychiatry 1997;63:204-209.

32 Penn RD, Savoy SM, Corcos D, Latash M, Gottlieb G, Parke B, Kroin JS: Intrathecal baclofen for severe spinal spasticity. N Engl J Med 1989;320:1517-1521.

>33 Hoffmann V, Schimrigk S, Islamova S, Hellwig K, Lukas C, Brune N, Poehlau D, Przuntek H, Mueller T: Efficacy and safety of repeated intrathecal triamcinolone acetonide application in progressive multiple sclerosis patients. J Neurol Sci 2003;211:81-84.

34 Krupp LB, LaRocca NG, Muir-Nash J, Steinberg AD: The fatigue severity scale. Application to patients with multiple sclerosis and systemic lupus erythematosus. Arch Neurol 1989;46:1121-1123.

35 Mathiowetz V: Test-retest reliability and convergent validity of the Fatigue Impact Scale for persons with multiple sclerosis. Am J Occup Ther 2003;57:389-395. 
- 36 Flachenecker P, Kuempfel T, Kallmann B, Gottschalk M, Grauer O, Rieckmann P, Trenkwalder C, Toyka KV: Fatigue in multiple sclerosis: a comparison of different rating scales and correlation to clinical parameters. Mult Scler 2002;8:523-526.

- 37 Branas P, Jordan R, Fry-Smith A, Burls A, Hyde C: Treatments for fatigue in multiple sclerosis: a rapid and systematic review. Health Technol Assess 2000;4:1-61.

- 38 Beenakker EA, Oparina TI, Hartgring A, Teelken A, Arutjunyan AV, De Keyser J: Cooling garment treatment in MS: clinical improvement and decrease in leukocyte $\mathrm{NO}$ production. Neurology 2001;57:892-894.

- 39 White AT, Wilson TE, Davis SL, Petajan JH: Effect of precooling on physical performance in multiple sclerosis. Mult Scler 2000;6:176180.

40 Flensner G, Lindencrona C: The coolingsuit: case studies of its influence on fatigue among eight individuals with multiple sclerosis. J Adv Nurs 2002;37:541-550.

-41 Schwid SR, Petrie MD, Murray R, Leitch J, Bowen J, Alquist A, Pelligrino R, Roberts A, Harper-Bennie J, Milan MD, Guisado R, Luna B, Montgomery L, Lamparter R, Ku YT, Lee H, Goldwater D, Cutter G, Webbon B; NASA/MS Cooling Study Group: A randomized controlled study of the acute and chronic effects of cooling therapy for MS. Neurology 2003;60:1955-1960.

-42 Mostert S, Kesselring J: Effects of a shortterm exercise training program on aerobic fitness, fatigue, health perception and activity level of subjects with multiple sclerosis. Mult Scler 2002;8:161-168.

-43 Surakka J, Romberg A, Ruutiainen J, Aunola S, Virtanen A, Karppi SL, Maentaka K: Effects of aerobic and strength exercise on motor fatigue in men and women with multiple sclerosis: a randomized controlled trial. Clin Rehabil 2004;18:737-748.

-44 Petajan JH, Gappmaier E, White AT, Spencer MK, Mino L, Hicks RW: Impact of aerobic training on fitness and quality of life in multiple sclerosis. Ann Neurol 1996;39:432441.

-45 Patti F, Ciancio MR, Reggio E, Lopes R, Palermo F, Cacopardo M, Reggio A: The impact of outpatient rehabilitation on quality of life in multiple sclerosis. J Neurol 2002;249: 1027-1033.

-46 Di Fabio RP, Soderberg J, Choi T, Hansen CR, Schapiro RT: Extended outpatient rehabilitation: its influence on symptom frequency, fatigue, and functional status for persons with progressive multiple sclerosis. Arch Phys Med Rehabil 1998;79:141-146.

-47 Mathiowetz V, Matuska KM, Murphy ME: Efficacy of an energy conservation course for persons with multiple sclerosis. Arch Phys Med Rehabil 2001;82:449-456.
48 Krupp LB, Coyle PK, Doscher C, Miller A, Cross AH, Jandorf L, Halper J, Johnson B, Morgante L, Grimson R: Fatigue therapy in multiple sclerosis: results of a double-blind, randomized, parallel trial of amantadine, pemoline, and placebo. Neurology 1995;45: 1956-1961.

49 Cohen RA, Fisher M: Amantadine treatment of fatigue associated with multiple sclerosis. Arch Neurol 1989;46:676-680.

50 Polman CH, Bertelsmann FW, de Waal R, van Diemen HA, Uitdehaag BM, van Loenen AC, Koetsier JC: 4-Aminopyridine is superior to 3,4-diaminopyridine in the treatment of patients with multiple sclerosis. Arch Neurol 1994;51:1136-1139:

51 Rossini PM, Pasqualetti P, Pozzilli C, Grasso MG, Millefiorini E, Graceffa A, Carlesimo GA, Zibellini G, Caltagirone C: Fatigue in progressive multiple sclerosis: results of a randomized, double-blind, placebo-controlled, crossover trial of oral 4-aminopyridine. Mult Scler 2001;7:354-358.

52 Sheean GL, Murray NM, Rothwell JC, Miller DH, Thompson AJ: An open-labelled clinical and electrophysiological study of 3,4-diaminopyridine in the treatment of fatigue in multiple sclerosis. Brain 1998;121:967-975.

53 Van Diemen HA, Polman CH, van Dongen TM, van Loenen AC, Nauta JJ, Taphoorn MJ, van Walbeek HK, Koetsier JC: The effect of 4-aminopyridine on clinical signs in multiple sclerosis: a randomized, placebo-controlled, double-blind, cross-over study. Ann Neurol 1992;32:123-130.

-54 Schwid SR, Petrie MD, McDermott MP, Tierney DS, Mason DH, Goodman AD: Quantitative assessment of sustained-release 4 -aminopyridine for symptomatic treatment of multiple sclerosis. Neurology 1997; 48:817-821.

55 Weinshenker BG, Penman M, Bass B, Ebers GC, Rice GP: A double-blind, randomized, crossover trial of pemoline in fatigue associated with multiple sclerosis. Neurology 1992; 42:1468-1471.

56 Tomassini V, Pozzilli C, Onesti E, Pasqualetti P, Marinelli F, Pisani A, Fieschi C: Comparison of the effects of acetyl L-carnitine and amantadine for the treatment of fatigue in multiple sclerosis: results of a pilot, randomised, double-blind, crossover trial. J Neurol Sci 2004;218:103-108.

57 Rammohan KW, Rosenberg JH, Lynn DJ, Blumenfeld AM, Pollak CP, Nagaraja HN: Efficacy and safety of modafinil (Provigil) for the treatment of fatigue in multiple sclerosis: a two-centre phase 2 study. J Neurol Neurosurg Psychiatry 2002;72:179-183.

58 Zifko UA, Rupp M, Schwarz S, Zifko HT, Maida EM: Modafinil in treatment of fatigue in multiple sclerosis. Results of an open-label study. J Neurol 2002;249:983-987.
59 Stankoff B, Waubant E, Confavreux C, Edan G, Debouverie M, Rumbach L, Moreau T, Pelletier J, Lubetzki C, Clanet M, and French Modafinil Study Group: Modafinil for fatigue in MS. A randomized placebo-controlled double-blind study. Neurology 2005; 64:1139-1143.

60 Wingerchuk DM, Benarroch EE, O'Brien PC, Keegan BM, Lucchinetti CF, Noseworthy JH, Weinshenker BG, Rodriguez M: A randomized controlled crossover trial of aspirin for fatigue in multiple sclerosis. Neurology 2005;64:1267-1269.

61 IFNB Multiple Sclerosis Study Group: Interferon- $\beta_{1 b}$ is effective in relapsing-remitting multiple sclerosis. Clinical results of a multicentre, randomized, double-blind, placebocontrolled trial. Neurology 1993;43:655661.

62 Jacobs LD, Cookfair DL, Rudick RA, Herndon RM, Richert JR, Salazar AM, Fischer JS, Goodkin DE, Granger CV, Simon JH, Alam JJ, Bartoszak DM, Bourdette DN, Braiman J, Brownscheidle CM, Coats ME, Cohan SL, Dougherty DS, Kinkel RP, Mass MK, Munschauer FE 3rd, Priore RL, Pullicino PM, Scherokman BJ, Whitham RH: Intramuscular interferon- $\beta_{1 \mathrm{a}}$ for disease progression in relapsing multiple sclerosis. Ann Neurol 1996;39:285-294.

63 PRISMS (Prevention of Relapses and Disability by Interferon- $\beta_{1 \mathrm{a}}$ Subcutaneously in Multiple Sclerosis) Study Group: Randomised double-blind placebo-controlled study of interferon- $\beta_{1 a}$ in relapsing-remitting multiple sclerosis. Lancet 1998;352: 1498-1504.

64 Metz LM, Patten SB, Archibald CJ, Bakker JI, Harris CJ, Patry DG, Bell RB, Yeung M, Murphy WF, Stoian CA, Billesberger K, Tillotson L, Peters S, McGowan D: The effect of immunomodulatory treatment on multiple sclerosis fatigue. J Neurol Neurosurg Psychiatry 2004;75:1045-1047.

65 Bennett M, Heard R: Treatment of multiple sclerosis with hyperbaric oxygen therapy. Undersea Hyperb Med 2001;28:117-122.

- 66 Sandyk R: Immediate recovery of cognitive functions and resolution of fatigue by treatment with weak electromagnetic fields in a patient with multiple sclerosis. Int J Neurosci 1997;90:59-74.

67 Mostert S, Kesselring J: Effect of pulsed magnetic field therapy on the level of fatigue in patients with MS - a randomised controlled trial. Mult Scler 2005;11:302-305.

68 Sindrup SH, Jensen TS: Pharmacologic treatment of pain in polyneuropathy. Neurology 2000;55:915-920.

69 Backonja M: Anticonvulsants for the treatment of neuropathic pain syndromes. Curr Pain Headache Rep 2003;7:39-42.

-70 Eisenberg E, Lurie Y, Braker C, Daoud D, Ishay A: Lamotrigine reduces painful diabetic neuropathy: a randomized, controlled study. Neurology 2001;57:505-509. 
71 Rosenstock J, Tuchman M, LaMoreaux L, Sharma U: Pregabalin for the treatment of painful diabetic peripheral neuropathy: a double-blind, placebo-controlled trial. Pain 2004;110:628-638.

72 Sabatowski R, Galvez R, Cherry DA, Jacquot F, Vincent E, Maisonobe P, Versavel M; 1008-045 Study Group: Pregabalin reduces pain and improves sleep and mood disturbances in patients with post-herpetic neuralgia: results of a randomised, placebo-controlled clinical trial. Pain 2004;109:26-35.

73 Houtchens MK, Richert JR, Sami A, Rose JW: Open label gabapentin treatment for pain in multiple sclerosis. Mult Scler 1997;3: 250-253.

74 D’Aleo G, Sessa E, Di Bella P, Rifici C, Restivo DA, Bramanti P: Topiramate modulation of R3 nociceptive reflex in multiple sclerosis patients suffering paroxysmal symptoms. J Neurol 2001;248:996-999.

-75 Kalman S, Osterberg A, Sorensen J, Boivie J, Bertler A: Morphine responsiveness in a group of well-defined multiple sclerosis patients: a study with intravenous morphine. Eur J Pain 2002;6:69-80.

-76 Attal N, Guirimand F, Brasseur L, Gaude V, Chauvin M, Bouhassira D: Effects of IV morphine in central pain: a randomized placebo-controlled study. Neurology 2002;58: 554-563.

77 Mattia C, Paoletti F, Coluzzi F, Boanelli A: New antidepressants in the treatment of neuropathic pain. A review. Minerva Anestesiol 2002;68:105-114.

78 Grothe DR, Scheckner B, Albano D: Treatment of pain syndromes with venlafaxine. Pharmacotherapy 2004;24:621-629.

-79 Sindrup SH, Bach FW, Madsen C, Gram LF, Jensen TS: Venlafaxine versus imipramine in painful polyneuropathy: a randomized, controlled trial. Neurology 2003;60:12841289.

-80 Iyengar S, Webster AA, Hemrick-Luecke SK, $\mathrm{Xu}$ JY, Simmons RM: Efficacy of duloxetine, a potent and balanced serotonin-norepinephrine reuptake inhibitor in persistent pain models in rats. J Pharmacol Exp Ther 2004;311:576-584.

-81 Schueler P, Seibel K, Chevts V, Schaffler K: Analgetische Wirkung des selektiven Noradrenalin-Wiederaufnahme-Hemmers Reboxetin. Nervenarzt 2002;73:149-154.

-82 Svendsen KB, Jensen TS, Bach FW: Does the cannabinoid dronabinol reduce central pain in multiple sclerosis? Randomised doubleblind placebo-controlled crossover trial. $\mathrm{Br}$ Med J 2004;329:253.

83 Philadelphia Panel: Philadelphia Panel evidence-based clinical practice guidelines on selected rehabilitation interventions for shoulder pain. Phys Ther 2001;81:17191730 .
84 Korthals-De Bos IB, Hoving JL, van Tulder MW, Rutten-van Molken MP, Ader HJ, de Vet HC, Koes BW, Vondeling H, Bouter LM: Cost effectiveness of physiotherapy, manual therapy, and general practitioner care for neck pain: economic evaluation alongside a randomised controlled trial. Br Med J 2003; 326:911.

85 Eccles M, Freemantle N, Mason J: North of England evidence-based guideline development project: summary guideline for nonsteroidal anti-inflammatory drugs versus basic analgesia in treating the pain of degenerative arthritis. The North of England NonSteroidal Anti-Inflammatory Drug Guideline Development Group. Br Med J 1998;317: 526-530.

86 Rio J, Nos C, Bonaventura I, Arroyo R, Genis D, Sureda B, Ara JR, Brieva L, Martin J, Saiz A, Sanchez Lopez F, Prieto JM, Roquer J, Dorado JF, Montalban X: Corticosteroids, ibuprofen, and acetaminophen for IFN- $\beta_{1 \mathrm{a}}$ flu symptoms in MS. A randomized trial. Neurology 2004;63:525-528.

87 Reess J, Haas J, Babriel K, Fuhlrott A, Fiola M: Both paracetamol and ibuprofen are equally effective in managing flu-like symptoms in relapsing-remitting multiple sclerosis patients during interferon- $\beta_{1 a}$ (AVONEX) therapy. Mult Scler 2002;8:15-18.

88 Philadelphia Panel: Philadelphia Panel evidence-based clinical practice guidelines on selected rehabilitation interventions for low back pain. Phys Ther 2001;81:1641-1674.

89 Furlan A, Brosseau L, Welch V, Wong J: Massage for low back pain. Cochrane Database Syst Rev 2002;(2):CD001929.

90 Gangji V, Appelboom T: Analgesic effect of intravenous pamidronate on chronic back pain due to osteoporotic vertebral fractures. Clin Rheumatol 1999;18:266-267.

91 Roe B, Williams K, Palmer M: Bladder training for urinary incontinence in adults. Cochrane Database Syst Rev 2000;CD001308.

92 Subak LL, Quesenberry CP, Posner SF, Cattolica E, Soghikian K: The effect of behavioural therapy on urinary incontinence: a randomized controlled trial. Obstet Gynecol 2002;100:72-78.

93 Eustice S, Roe B, Paterson J: Prompted voiding for the management of urinary incontinence in adults (Cochrane Review). Cochrane Database Syst Rev 2000;(2): CD002113.

94 Hay-Smith J, Herbison P, Ellis G, Moore K: Anticholinergic drugs versus placebo for overactive bladder syndrome in adults. Cochrane Database Syst Rev 2002;CD003781.

95 Nygaard IE, Kreder KJ, Lepic MM, Fountain KA, Rhomberg AT: Efficacy of pelvic floor muscle exercises in women with stress, urge, and mixed urinary incontinence. $\mathrm{Am} \mathrm{J} \mathrm{Ob-}$ stet Gynecol 1996;174:120-125.

$\$ 96$ Vahtera T, Haaranen M, Viramo-Koskela AL, Ruutiainen J: Pelvic floor rehabilitation is effective in patients with multiple sclerosis. Clin Rehabil 1997;11:211-219.
97 Cardozo L, Chapple CR, Toozs-Hobson P, Grosse-Freese M, Bulitta M, Lehmacher W, Strosser W, Ballering-Bruhl B, Schafer M: Efficacy of trospium chloride in patients with detrusor instability: a placebo-controlled, randomized, double-blind, multicentre clinical trial. BJU Int 2000;85:659664.

98 Drutz HP, Appell RA, Gleason D, Klimberg I, Radomski S: Clinical efficacy and safety of tolterodine compared to oxybutynin and placebo in patients with overactive bladder. Int Urogynecol J Pelvic Floor Dysfunct 1999; 10:283-289.

99 Jacquetin B, Wyndaele J: Tolterodine reduces the number of urge incontinence episodes in patients with an overactive bladder. Eur J Obstet Gynecol Reprod Biol 2001; 98:97-102.

100 Stoehrer M, Madersbacher H, Richter R, Wehnert J, Dreikorn K: Efficacy and safety of propiverine in SCI-patients suffering from detrusor hyperreflexia - a doubleblind, placebo-controlled clinical trial. Spinal Cord 1999;37:196-200.

101 Chancellor MB, Appell RA, Sathyan G, Gupta SK: A comparison of the effects on saliva output of oxybutynin chloride and tolterodine tartrate. Clin Ther 2001;23: 753-760.

102 Todorova A, Vonderheid-Guth B, Dimpfel W: Effects of tolterodine, trospium chloride, and oxybutynin on the central nervous system. J Clin Pharmacol 2001;41: 636-644.

103 Haeusler G, Leitich H, van Trotsenburg M, Kaider A, Tempfer CB: Drug therapy of urinary urge incontinence: a systematic review. Obstet Gynecol 2002:100:1003-1016.

104 Chapple C: Darifenacin is effective in improving the major symptoms of overactive bladder: a pooled analysis of phase III studies. Eur Urol 2004;(suppl 3):A512.

105 Cardozo L, Lisec M, Millard R, van Vierssen Trip O, Kuzmin I, Drogendijk TE, Huang M, Ridder AM: Randomized, double-blind placebo-controlled trial of the once-daily antimuscarinic agent solifenacin succinate in patients with overactive bladder. J Urol 2004;172:1919-1924.

106 Chapple CR, Rechberger T, Al-Shukri S, and the YM-905 Study Group: Randomized, double-blind placebo- and tolterodine-controlled trial of the once-daily antimuscarinic agent Solifenacin in patients with symptomatic overactive bladder. BJU Int 2004b; 93:303-310.

107 Abrams P, Amarenco G, Bakke A, and the European Tamsulosin Neurogenic Lower Urinary Tract Dysfunction Study Group: Tamsulosin: efficacy and safety in patients with neurogenic lower urinary tract dysfunction due to suprasacral spinal cord injury. J Urol 2003;170:1242-1251. 
108 Taylor MC, Bates CP: A double-blind crossover trial of baclofen - a new treatment for the unstable bladder syndrome. Br J Urol 1979;51:504-505.

- 109 Steers WD, Meythaler JM, Haworth C, Herrell D, Park TS: Effects of acute bolus and chronic continuous intrathecal baclofen on genitourinary dysfunction due to spinal cord pathology. J Urol 1992;148: 1849-1855.

-110 Hoverd PA, Fowler CJ: Desmopressin in the treatment of daytime urinary frequency in patients with multiple sclerosis. J Neurol Neurosurg Psychiatry 1998;65:778-780.

-111 Valiquette G, Herbert J, Maede-D’Alisera P: Desmopressin in the management of nocturia in patients with multiple sclerosis. A double-blind, crossover trial. Arch Neurol 1996;53:1270-1275.

-112 Eckford SD, Carter PG, Jackson SR, Penney MD, Abrams P: An open, in-patient incremental safety and efficacy study of desmopressin in women with multiple sclerosis and nocturia. Br J Urol 1995;76:459-463.

-113 Tubridy N, Addison R, Schon F: Long term use of desmopressin for urinary symptoms in multiple sclerosis. Mult Scler 1999;5: 416-417.

- 114 Naber KG, Bergman B, Bishop MC, Bjerklund-Johansen TE, Botto $H$, Lobel $B$, Jinenez Cruz F, Selvaggi FP: Urinary Tract Infection (UTI) Working Group of the Health Care Office (HCO) of the European Association of Urology (EAU) EAU guidelines for the management of urinary and male genital tract infections. Urinary Tract Infection (UTI) Working Group of the Health Care Office (HCO) of the European Association of Urology (EAU). Eur Urol 2001;40:576-588.

-115 Sauerwein D: Urinary tract infection in patients with neurogenic bladder dysfunction. Int J Antimicrob Agents 2002;19:592597.

-116 Banovac K, Wade N, Gonzalez F, Walsh B, Rhamy RK: Decreased incidence of urinary tract infections in patients with spinal cord injury: effect of methenamine. J Am Paraplegia Soc 1991;14:52-54.

117 Fuenfstueck R, Straube E, Schildbach O, Tietz U: Prevention of reinfection by L-methionine in patients with recurrent urinary tract infection. Med Klin 1997;92:574-581.

- 118 Castello T, Girona L, Gomez MR, Mena Mur A, Garcia L: The possible value of ascorbic acid as a prophylactic agent for urinary tract infection. Spinal Cord 1996;34: 592-593.

119 Mohler JL, Cowen DL, Flanigan RC: Suppression and treatment of urinary tract infection in patients with an intermittently catheterized neurogenic bladder. J Urol 1997;138:336-340.
120 Morton SC, Shekelle PG, Adams JL, Bennett $\mathrm{C}$, Dobkin BH, Montgomerie J, Vickrey BG: Antimicrobial prophylaxis for urinary tract infection in persons with spinal cord dysfunction. Arch Phys Med Rehabil 2002;83:129-138.

121 Oakeshott P, Hunt GM: Intermittent selfcatheterization for patients with urinary incontinence or difficulty emptying the bladder. Br J Gen Pract 1992;42:253-255.

122 Wyndaele JJ: Complications of intermittent catheterization: their prevention and treatment. Spinal Cord 2002;40:536-541.

123 Giannantoni A, Scivoletto G, Di Stasi SM, Silecchia A, Finazzi-Agro E, Micali I, Castellano V: Clean intermittent catheterization and prevention of renal disease in spinal cord injury patients. Spinal Cord 1998; 36:29-32.

124 Lehtoranta K, Tainio H, Lukkari-Lax E, Hakonen T, Tammela TL: Pharmacokinetics, efficacy, and safety of intravesical formulation of oxybutynin in patients with detrusor overactivity. Scand J Urol Nephrol 2002;36:18-24.

125 Froehlich G, Burmeister S, Wiedemann A, Bulitta M: Intravesical instillation of trospium chloride, oxybutynin and verapamil for relaxation of the bladder detrusor muscle. A placebo-controlled, randomized clinical test. Arzneimittelforschung 1998; 48:486-491.

126 De Seze M, Wiart L, Joseph PA, Dosque JP, Mazaux JM, Barat M: Capsaicin and neurogenic detrusor hyperreflexia: a doubleblind placebo-controlled study in 20 patients with spinal cord lesions. Neurourol Urodyn 1998;17:513-523.

127 Giannantoni A, Di Stasi SM, Stephen RL, Navarra P, Scivoletto G, Mearini E, Porena $\mathrm{M}$ : Intravesical capsaicin versus resiniferatoxin in patients with detrusor hyperreflexia: a prospective randomized study. J Urol 2002;167:1710-1714.

128 Phelan MW, Franks M, Somogyi GT, Yokoyama T, Fraser MO, Lavelle JP, Yoshimura N, Chancellor MB: Botulinum toxin urethral sphincter injection to restore bladder emptying in men and women with voiding dysfunction. J Urol 2001;165:1107-1110.

129 Schurch B, Stoehrer M, Kramer G, Schmid DM, Gaul G, Hauri D: Botulinum-A toxin for treating detrusor hyperreflexia in spinal cord injured patients: a new alternative to anticholinergic drugs? Preliminary results. J Urol 2000;164:692-697.

-130 Reitz A, Stoehrer M, Kramer G, Del Popolo G, Chartier-Kastler E, Pannek J, Burgdorfer H, Gocking K, Madersbacher H, Schumacher S, Richter R, von Tobel J, Schurch B: European experience of 200 cases treated with botulinum-A toxin injections into the detrusor muscle for urinary incontinence due to neurogenic detrusor overactivity. Eur Urol 2004;45:510-515.
131 Chartier-Kastler EJ, Ruud Bosch JL, Perrigot M, Chancellor MB, Richard F, Denys $\mathrm{P}$ : Long-term results of sacral nerve stimulation (S3) for the treatment of neurogenic refractory urge incontinence related to detrusor hyperreflexia. J Urol 2000;164:14761480 .

132 Wiesel PH, Norton C, Brazzelli M: Management of faecal incontinence and constipation in adults with central neurological diseases. Cochrane Database Syst Rev 2001;CD002115.

133 Norton C, Hosker G, Brazzelli M: Biofeedback and/or sphincter exercises for the treatment of faecal incontinence in adults. Cochrane Database Syst Rev 2000; CD002111.

134 Hosker G, Norton C, Brazzelli M: Electrical stimulation for faecal incontinence in adults. Cochrane Database Syst Rev 2000;CD001310.

135 DasGupta R, Fowler CJ: Bladder, bowel and sexual dysfunction in multiple sclerosis: management strategies. Drugs 2003;63: 153-166.

136 McCabe MP: Exacerbation of symptoms among people with multiple sclerosis: impact on sexuality and relationships over time. Arch Sex Behav 2004;33:593-601.

137 Foley FW, LaRocca NG, Sanders AS, Zemon V: Rehabilitation of intimacy and sexual dysfunction in couples with multiple sclerosis. Mult Scler 2001;7:417-421.

138 Fowler CJ, Miller JR, Sharief MK, Hussain IF, Stecher VJ, Sweeney M: A double-blind, randomised study of sildenafil citrate for erectile dysfunction in men with multiple sclerosis. J Neurol Neurosurg Psychiatry 2005;76:700-705

139 Dula E, Keating W, Siami PF, Edmonds A, O'Neil J, Buttler S: Efficacy and safety of fixed-dose and dose-optimization regimens of sublingual apomorphine versus placebo in men with erectile dysfunction. The Apomorphine Study Group. Urology 2000;56:130-135.

140 Vogt HJ, Brandl P, Kockott G, Schmitz JR, Wiegand $\mathrm{MH}$, Schadrack J, Gierend M: Double-blind, placebo-controlled safety and efficacy trial with yohimbine hydrochloride in the treatment of non-organic erectile dysfunction. Int J Impot Res 1997; 9:155-161.

141 Davis SR: The effects of tibolone on mood and libido. Menopause 2002;9:162-170.

142 Laan E, van Lunsen RH, Everaerd W: The effects of tibolone on vaginal blood flow, sexual desire and arousability in postmenopausal women. Climacteric 2001;4:28-41.

143 DasGupta R, Wiseman OJ, Kanabar G, Fowler CJ, Mikol DD: Efficacy of sildenafil in the treatment of female sexual dysfunction due to multiple sclerosis. J Urol 2004; 171:1189-1193. 
144 Godschalk MF, Chen J, Katz PG, Mulligan T: Treatment of erectile failure with prostaglandin $\mathrm{E}_{1}$ : a double-blind, placebo-controlled, dose-response study. J Urol 1994; 151:1530-1532.

145 Linet OI, Ogrinc FG: Efficacy and safety of intracavernosal alprostadil in men with erectile dysfunction. The Alprostadil Study Group. N Engl J Med 1996;334:873-877.

-146 Padma-Nathan H, Hellstrom WJ, Kaiser FE, Labasky RF, Lue TF, Nolten WE, Norwood PC, Peterson CA, Shabsigh R, Tam PY: Treatment of men with erectile dysfunction with transurethral alprostadil. Medicated Urethral System for Erection (MUSE) Study Group. N Engl J Med 1997; 336:1-7.

147 Lewis RW, Witherington R: External vacuum therapy for erectile dysfunction: use and results. World J Urol 1997;15:78-82.

148 Evans C: The use of penile prostheses in the treatment of impotence. Br J Urol 1998, 81: 591-598.

149 Albrecht H, Schwecht M, Poellmann W, Parag D, Erasmus LP, Koenig N: Local ice application in therapy of kinetic limb ataxia. Clinical assessment of positive treatment effects in patients with multiple sclerosis. Nervenarzt 1998;69:1066-1073.

-150 Trouillas P, Takayanagi T, Hallett M, Currier RD, Subramony SH, Wessel K, Bryer A, Diener HC, Massaquoi S, Gomez CM, Coutinho P, Ben Hamida M, Campanella G, Filla A, Schut L, Timann D, Honnorat J, Nighoghossian N, Manyam B: International Cooperative Ataxia Rating Scale for pharmacological assessment of the cerebellar syndrome. The Ataxia Neuropharmacology Committee of the World Federation of Neurology. J Neurol Sci 1997;145:205211.

-151 Meshack RP, Norman KE: A randomized controlled trial of the effects of weights on amplitude and frequency of postural hand tremor in people with Parkinson's disease. Clin Rehabil 2002;16:481-492.

- 152 Feys P, Helsen W, Liu X, Mooren D, Albrecht $\mathrm{H}$, Nuttin B, Ketelaer P: Effects of peripheral cooling on intention tremor in multiple sclerosis. J Neurol Neurosurg Psychiatry 2005;76:373-379.

-153 Koller WC: Pharmacologic trials in the treatment of cerebellar tremor. Arch Neurol 1984;41:280-281.

-154 Sechi GP, Zuddas M, Piredda M, Agnetti V, Sau G, Piras ML, Tanca S, Rosati G: Treatment of cerebellar tremors with carbamazepine: a controlled trial with long-term follow-up. Neurology 1989;39:1113-1115.

- 155 Sechi GP, Agnetti V, Sulas FMI, Sau GF, Corda D, Pitzolu MG, Rosati G: Effects of topiramate in patients with cerebellar tremor. Prog Neuropsychopharmacol Biol Psychiatry 2003;27:1023-1027.
156 Trelles L, Trelles JO, Castro C, Altamirano $\mathrm{J}$, Benzaquen M: Successful treatment of two cases of intention tremor with clonazepam. Ann Neurol 1984;16:621.

157 Trouillas P, Brudon F, Adeleine P: Improvement of cerebellar ataxia with levorotatory form of 5-hydroxytryptophan. A doubleblind study with quantified data processing. Arch Neurol 1988;45:1217-1222.

158 Gbadamosi J, Buhmann C, Moench A, Heesen C: Failure of ondansetron in treating cerebellar tremor in MS patients - an open-label pilot study. Acta Neurol Scand 2001;104:308-311.

159 Bier JC, Dethy S, Hildebrand J, Jacquy J, Manto M, Martin JJ, Seeldrayers P: Effects of the oral form of ondansetron on cerebellar dysfunction. A multi-centre doubleblind study. J Neurol 2003;250:693-697.

160 Rice GP, Lesaux J, Vandervoort P, Macewan L, Ebers GC: Ondansetron, a 5- $\mathrm{HT}_{3}$ antagonist, improves cerebellar tremor. J Neurol Neurosurg Psychiatry 1997;62:282-284.

161 Hallett M: Isoniazid and action tremor in multiple sclerosis. J Neurol Neurosurg Psychiatry 1985;48:957.

162 Duquette P, Pleines J, du Souich P: Isoniazid for tremor in multiple sclerosis: a controlled trial. Neurology 1985;35:17721775.

163 Wessel K, Langenberger K, Nitschke MF, Koempf D: Double-blind crossover study with physostigmine in patients with degenerative cerebellar diseases. Arch Neurol 1997;54:397-400.

164 Clifford DB: Tetrahydrocannabinol for tremor in multiple sclerosis. Ann Neurol 1993;13:669-671.

165 Wishart HA, Roberts DW, Roth RM, McDonald BC, Coffey DJ, Mamourian AC, Hartley C, Flashman LA, Fadul CE, Saykin AJ: Chronic deep brain stimulation for the treatment of tremor in multiple sclerosis: review and case reports. J Neurol Neurosurg Psychiatry 2003;74:1392-1397.

166 Berk C, Carr J, Sinden M, Martzke J, Honey CR: Thalamic deep brain stimulation for the treatment of tremor due to multiple sclerosis: a prospective study of tremor and quality of life. J Neurosurg 2002;97:815820 .

167 Hooper J, Taylor R, Pentland B, Whittle IR: A prospective study of thalamic deep brain stimulation for the treatment of movement disorders in multiple sclerosis. Br J Neurosurg 2002;16:102-109.

168 Alusi SH, Aziz TZ, Glickman S, Jahanshahi M, Stein JF, Bain PG: Stereotactic lesional surgery for the treatment of tremor in multiple sclerosis: a prospective case-controlled study. Brain 2001;124:1576-1589.

169 Goverover Y, Chiaravalloti N, DeLuca J: The relationship between self-awareness of neurobehavioral symptoms, cognitive functioning, and emotional symptoms in multiple sclerosis. Mult Scler 2005;11:203212.
170 Niemann H, Ruff RM, Baser CA: Computer-assisted attention retraining in head injured individuals: a controlled efficacy study of an outpatient program. J Consult Clin Psychol 1990;58:811-817.

171 Plohmann AM, Kappos L, Ammann W, Thordai A, Wittwer A, Huber S, Bellaiche Y, Lechner-Scott J: Computer-assisted retraining of attentional impairments in patients with multiple sclerosis. J Neurol Neurosurg Psychiatry 1998;64:455-462.

172 Wood RL, Fussey I: Computer-based cognitive retraining: a controlled study. Int Disabil Stud 1987;9:149-153.

173 Mendozzi L, Pugnetti L: Computer-assisted memory retraining of patients with multiple sclerosis. Ital J Neurol Sci 1998;19: 431-434.

174 Freeman MR, Mittenberg W, Dicowden M, Bat-Ami M: Executive and compensatory memory retraining in traumatic brain injury. Brain Inj 1992;6:65-70.

175 Wilson BA, Evans JJ, Emslie H, Malinek V: Evaluation of NeuroPage: a new memory aid. J Neurol Neurosurg Psychiatry 1997; 63:113-115.

176 Chiaravalloti ND, DeLuca J, Moore NB, Ricker JH: Treating learning impairments improves memory performance in multiple sclerosis: a randomized clinical trial. Mult Scler 2005; 11:58-68.

177 Benedict RH, Shapiro A, Priore R, Miller C, Munschauer F, Jacobs L: Neuropsychological counselling improves social behaviour in cognitively-impaired multiple sclerosis patients. Mult Scler 2000;6:391-396.

178 Jonsson A, Korfitzen EM, Heltberg A, Ravnborg $\mathrm{MH}$, Byskov-Ottosen E: Effects of neuropsychological treatment in patients with multiple sclerosis. Acta Neurol Scand 1993;88:394-400.

179 Mendoza RJ, Pittenger DJ, Weinstein CS: Unit management of depression of patients with multiple sclerosis using cognitive remediation strategies: a preliminary study. Neurorehabil Neural Repair 2001;15:9-14.

180 Krupp LB, Christodolou C, Melville P, Scherl WF, MacAllister WS, Elkins LE: Donepezil improved memory in multiple sclerosis in a randomized clinical trial. Neurology 2004;63:1579-1585.

181 Greene YM, Tariot PN, Wishart H, Cox C, Holt CJ, Schwid S, Noviasky J: A 12-week, open trial of donepezil hydrochloride in patients with multiple sclerosis and associated cognitive impairments. J Clin Psychopharmacol 2000;20:350-356.

182 Sailer M, Heinze HJ, Schoenfeld MA, Hauser U, Smid HG: Amantadine influences cognitive processing in patients with multiple sclerosis. Pharmacopsychiatry 2000;3: 28-37.

183 Geisler MW, Sliwinski M, Coyle PK: The effects of amantadine and pemoline on cognitive functioning in MS. Arch Neurol 1996;53:185-188. 
-184 Pliskin NH, Hamer DP, Goldstein DS, Towle VL, Reder AT, Noronha A, Arnason BG: Improved delayed visual reproduction test performance in multiple sclerosis patients receiving interferon- $\beta_{1 b}$. Neurology 1996;47:1463-1468.

185 Barak Y, Achiron A: Effect of interferon- $\beta_{1 b}$ on cognitive functions in multiple sclerosis. Eur Neurol 2002;47:11-14.

-186 Selby MJ, Ling N, Williams JM, Dawson A: Interferon- $\beta_{1 b}$ in verbal memory functioning of patients with relapsing-remitting multiple sclerosis. Percept Mot Skills 1998; 86:1099-1106.

-187 Fischer JS, Priore RL, Jacobs LD, Cookfair DL, Rudick RA, Herndon RM, Richert JR, Salazar AM, Goodkin DE, Granger CV, Simon JH, Grafman JH, Lezak MD, O’Reilly Hovey KM, Perkins KK, Barilla-Clark D, Schacter M, Shucard DW, Davidson AL, Wende KE, Bourdette DN, KooijmansCoutinho MF: Neuropsychological effects of interferon- $\beta_{1 \mathrm{a}}$ in relapsing multiple sclerosis. Multiple Sclerosis Collaborative Research Group. Ann Neurol 2000;48:885892.

188 Weinstein A, Schwid SR, Schiffer RB, McDermott MP, Giang DW, Goodman AD: Neuropsychologic status in multiple sclerosis after treatment with glatiramer. Arch Neurol 1999;56:319-324.

-189 Goodkin DE, Ransohoff RM, Rudick RA: Experimental therapies for multiple sclerosis: current status. Cleve Clin J Med 1992; 59:63-74.

190 Chwastiak L, Ehde DM, Gibbons LE, Sullivan M, Bowen JD, Kraft GH: Depressive symptoms and severity of illness in multiple sclerosis: epidemiologic study of a large community sample. Am J Psychiatry 2002; 159:1862-1868.

-191 Schiffer RB, Wineman NM: Antidepressant pharmacotherapy of depression associated with multiple sclerosis. Am J Psychiatry 1990;147:1493-1497.

-192 Schwartz CE: Teaching coping skills enhances quality of life more than peer support: results of a randomized trial with multiple sclerosis patients. Health Psychol 1999;18:211-220.

-193 Crawford JD, McIvor GP: Group psychotherapy: benefits in multiple sclerosis. Arch Phys Med Rehabil 1985;66:810-813.

-194 Mohr DC, Boudewyn AC, Goodkin DE, Bostrom A, Epstein L: Comparative outcomes for individual cognitive-behaviour therapy, supportive-expressive group psychotherapy, and sertraline for the treatment of depression in multiple sclerosis. J Consult Clin Psychol 2001;69:942-949.

- 195 Mohr DC, Burke H, Beckner V, Merluzzi N: A preliminary report on a skills-based telephone-administered peer support programme for patients with multiple sclerosis. Mult Scler 2005;11:222-226.
196 Gil D, Hatcher S: Antidepressants for depression in medical illness. Cochrane Database Syst Rev 2000;(4):CD001312.

197 Barak Y, Ur E, Achiron A: Moclobemide treatment in multiple sclerosis patients with comorbid depression: an open-label safety trial. J Neuropsychiatry Clin Neurosci 1999;11:271-273.

198 Wiffen P, Collins S, McQuay H, Carroll D, Jadad A, Moore A: Anticonvulsant drugs for acute and chronic pain. Cochrane Database Syst Rev 2000;CD001133.

199 Leandri M, Lundardi G, Inglese M, Messmer-Uccelli M, Mancardi GL, Gottlieb A, Solaro C: Lamotrigine in trigeminal neuralgia secondary to multiple sclerosis. J Neurol 2000;247:556-558.

200 Ramsaransing G, Zwanikken C, De Keyser $\mathrm{J}$ : Worsening of symptoms of multiple sclerosis associated with carbamazepine. $\mathrm{Br}$ Med J 2000;320:1113.

201 Fromm GH, Terrence CF, Chattha AS: Baclofen in the treatment of trigeminal neuralgia: double-blind study and long-term follow-up. Ann Neurol 1984;15:240-244.

202 Zakrzewska JM, Chaudhry Z, Nurmikko TJ, Patton DW, Mullens EL: Lamotrigine (lamictal) in refractory trigeminal neuralgia: results from a double-blind placebo controlled crossover trial. Pain 1997;73: 223-230.

203 Solaro C, Messmer UM, Uccelli A, Leandri M, Mancardi GL: Low-dose gabapentin combined with either lamotrigine or carbamazepine can be useful therapies for trigeminal neuralgia in multiple sclerosis. Eur Neurol 2000;44:45-48.

204 Yetimalar Y, Gurgor N, Basoglu M: Clinical efficacy of gabapentin for paroxysmal symptoms in multiple sclerosis. Acta Neurol Scand 2004;109:430-431.

205 Solaro C, Uccelli MM, Brichetto G, Gasperini C, Mancardi G: Topiramate relieves idiopathic and symptomatic trigeminal neuralgia. J Pain Symptom Manage 2001;21: 367-368.

206 Sindrup SH, Jensen TS: Pharmacotherapy of trigeminal neuralgia. Clin J Pain 2002; 18:22-27.

207 DMKG Study Group: Misoprostol in the treatment of trigeminal neuralgia associated with multiple sclerosis. J Neurol 2003; 250:542-545.

208 Jho HD, Lunsford LD: Percutaneous retrogasserian glycerol rhizotomy. Current technique and results. Neurosurg Clin N Am 1997;8:63-74.

209 Broggi G, Ferroli P, Franzini A, Pluderi M, La Mantia L, Milanese C: Role of microvascular decompression in trigeminal neuralgia and multiple sclerosis. Lancet 1999;354: 1878-1879.

210 Kondziolka D, Lunsford LD, Flickinger JC: Stereotactic radiosurgery for the treatment of trigeminal neuralgia. Clin J Pain 2002; $18: 42-47$.
211 Cheng JS, Sanchez-Mejia RO, Limbo M, Ward MM, Barbaro NM: Management of medically refractory trigeminal neuralgia in patients with multiple sclerosis. Neurosurg Focus 2005;18(5) (www.medscape. com/viewarticle/505388).

212 Solaro C, Lunardi GL, Capello E, Inglese M, Messmer UM, Uccelli A, Mancardi GL: An open-label trial of gabapentin treatment of paroxysmal symptoms in multiple sclerosis patients. Neurology 1998;51:609-611.

213 Cianchetti C, Zuddas A, Randazzo AP, Perra L, Marrosu MG: Lamotrigine adjunctive therapy in painful phenomena in MS: preliminary observations. Neurology 1999;53: 433.

214 Blakeley J, Jankovic J: Secondary paroxysmal dyskinesias. Mov Disord 2002;17:726734.

215 Sakurai M, Kanazawa I: Positive symptoms in multiple sclerosis: their treatment with sodium channel blockers, lidocaine and mexiletine. J Neurol Sci 1999;162:162-168.

216 Cakmur R, Ozturk V, Uzunel F, Donmez B, Idiman F: Comparison of preseptal and pretarsal injections of botulinum toxin in the treatment of blepharospasm and hemifacial spasm. J Neurol 2002;249:64-68.

217 Averbuch-Heller L, Tusa RJ, Fuhry L, Rottach KG, Ganser GL, Heide W, Buettner U, Leigh RJ: A double-blind controlled study of gabapentin and baclofen as treatment for acquired nystagmus. Ann Neurol 1997;41: 818-825.

218 Bandini F, Castello E, Mazzella L, Mancardi GL, Solaro C: Gabapentin but not vigabatrin is effective in the treatment of acquired nystagmus in multiple sclerosis: how valid is the GABAergic hypothesis? J Neurol Neurosurg Psychiatry 2001;71:107110.

219 Starck M, Albrecht H, Poellmann W, Straube A, Dieterich M: Drug therapy for acquired pendular nystagmus in multiple sclerosis. J Neurol 1997;244:9-16.

220 Dieterich M, Straube A, Brandt T, Paulus W, Buettner U: The effects of baclofen and cholinergic drugs on upbeat and downbeat nystagmus. J Neurol Neurosurg Psychiatry 1991;54:627-632.

221 Strupp M, Schueler O, Krafczyk S, Jahn K, Schautzer F, Buttner U, Brandt T: Treatment of downbeat nystagmus with 3,4-diaminopyridine. Neurology 2003;61:165170.

222 Glasauer S, Kalla R, Buettner U, Strupp M, Brandt T: 4-Aminopyridine restores visual ocular motor function in upbeat nystagmus. J Neurol Neurosurg Psychiatry 2005; 76:451-453.

223 Kalla R, Glasauer S, Schautzer F, Lehnen N, Buettner U, Strupp M, Brandt T: 4-Aminopyridine improves downbeat nystagmus, smooth pursuit, and VOR gain. Neurology 2004;62:1228-1229. 
-224 Hartelius L, Runmarker B, Andersen O: Prevalence and characteristics of dysarthria in a multiple-sclerosis incidence cohort: relation to neurological data. Folia Phoniatr Logop 2000;52:160-177.

225 Yorkston KM, Spencer KA, Duffy JR, Beukelman DR, Golper LA, Miller RM, Strand EA: Behavioural management of respiratory/phonatory dysfunction from dysarthria: a systemic review of the evidence. J Med Speech Lang Pathol 2003;11:xiiixxxviii.

-226 Darley FL, Brown JR, Goldstein NP: Dysarthria in multiple sclerosis. J Speech Hear Res 1972;15:229-245.

-227 Samar VJ, Metz DE: Criterion validity of speech intelligibility rating scale procedures for the hearing-impaired population. J Speech Hear Res 1988;31:307-316.

-228 Enderby P, Emerson J: Speech and language therapy: does it work? BMJ 1996;312:16551658.

-229 Jacobson BH, Johnson A, Grywalsk C, Silbergleit A, Jacobson G, Benninger M: The voice handicap index (VHI): development and validation. Am J Speech Lang Pathol 1997;6:66-70.

-230 Hogikyan ND, Sethuraman G: Validation of an instrument to measure voice-related quality of life (V-RQOL). J Voice 1999;13: 557-569.

231 Spencer KA, Yorkston KM, Duffy JR: Behavioural management of respiratory/phonatory dysfunction from dysarthria: a flow chart for guidance in clinical decisionmaking. J Med Speech Lang Pathol 2003;11: xxxix-lxi.

-232 Merson RM, Rolnick MI: Speech-language pathology and dysphagia in multiple sclerosis. Phys Med Rehabil Clin N Am 1998;9: 631-641.

233 Miller Sorensen P: Dysarthria; in Burks JS, Johnson KP (EDS): Multiple Sclerosis. Diagnosis, Medical Management, and Rehabilitation. New York, Demos, 2000, pp 388391.

234 Deane KH, Whurr R, Playford ED, Ben Shlomo Y, Clarke CE: Speech and language therapy for dysarthria in Parkinson's disease. Cochrane Database Syst Rev 2001; CD002812.

235 Deane KH, Whurr R, Playford ED, Ben Shlomo Y, Clarke CE: A comparison of speech and language therapy techniques for dysarthria in Parkinson's disease. Cochrane Database Syst Rev 2002;CD002814.

-236 De Swart BJ, Willemsen SC, Maassen BA, Horstink MW: Improvement of voicing in patients with Parkinson's disease by speech therapy. Neurology 2003;60:498-500.

-237 Sapir S, Pawlas A, Ramig LO, Seeley E, Fox $\mathrm{C}$, Corboy J: Effects in intensive phonatoryrespiratory treatment (LSVT) on voice in two individuals with multiple sclerosis. J Med Speech Lang Pathol 2001;9:141-151.
238 Vogel M: Behandlung der Dysarthrie; in Springer L, Schrey-Dern D (eds): Dysarthrie. Grundlagen, Diagnostik, Therapie. Stuttgart, Thieme, 1998, pp 99-130.

239 Duffy JR, Yorkston KM: Medical interventions for spasmodic dysphonia and some related conditions: a systematic review. J Med Speech Lang Pathol 2003;11:ix-Iviii.

240 Blitzer A, Brin MF, Stewart CF: Botulinum toxin management of spasmodic dysphonia (laryngeal dystonia): a 12-year experience in more than 900 patients. Laryngoscope 1998; 108:1435-1441.

241 Rontal E, Rontal M, Wald J, Rontal D: Botulinum toxin injection in the treatment of vocal fold paralysis associated with multiple sclerosis. A case report. J Voice 1999;13: 274-279.

242 Friedrich G, De Jong F, Mahieu HF, Benninger MS, Isshiki N: Laryngeal framework surgery: a proposal for classification and nomenclature by the Phonosurgery Committee of the European Laryngological Society. Eur Arch Otorhinolaryngol 2001; 258:389-396

243 Yorkston KM, Spencer KA, Duffy JR, Beukelman DR, Golper LA, Miller RM, Strand RA, Sullivan M: Evidence-based practice guidelines for dysarthria: management of velopharyngeal function. J Med Speech Lang Pathol 2001;9:257-273.

244 Hanson EK, Yorkston KM, Beukelman DR Speech supplementation techniques for dysarthria: a systematic review. J Med Speech Lang Pathol 2004;12:ix-xxix.

245 Glennen S, DeCoste D: Handbook of Augmentation and Alternative Communication. San Diego, Singular Publishing, 1997.

246 The National Collaborating Centre for Chronic Conditions: Multiple sclerosis national guideline for diagnosis and management in primary and secondary care. London, Royal College of Physicians, 2004, pp 120-123.

247 McHorney CA, Robbins J, Lomax K, Rosenbek JC, Chignell K, Kramer AE, Bricker DE: The SWAL-QOL and SWAL-CARE outcomes tool for oropharyngeal dysphagia in adults. III. Documentation of reliability and validity. Dysphagia 2002;17:97-114.

248 Prosiegel M, Schleicher M, Yassouridis Y: Success of rehabilitation and predictors of outcome in patients with neurogenic dysphagia. Zentralbl Neurochir 1999;58:4748.

249 Cook IJ, Kahrilas PJ: AGA technical review on management of oropharyngeal dysphagia. Gastroenterology 1999;116:455-478.

250 Bath PMW, Bath FJ, Smithhard DG: Interventions for dysphagia in acute stroke. Cochrane Database Syst Rev 2000;(2): CD000323.
251 Agency for Health Care Policy and Research: Diagnosis and treatment of swallowing disorders (dysphagia) in acute-care stroke patients. AHCPR Publication 1999 No 99-E024, Rockville, MD. www.ahcpr. gov/clinic/tp/dysphtp.htm.

252 Huckabee ML, Cannito MP: Outcome of swallowing rehabilitation in chronic brainstem dysphagia: a retrospective evaluation. Dysphagia 1999;14:93-109.

253 Schurr MJ, Ebner KA, Maser AL, Sperling KB, Helgerson RB, Harms B: Formal swallowing evaluation and therapy after traumatic brain injury improves dysphagia outcomes. J Trauma 1999;46:817-821.

254 Freed ML, Freed L, Chatburn RL, Christian M: Electrical stimulation for swallowing disorders caused by stroke. Respir Care 2001;46:466-474.

255 Shaker R, Easterling C, Kern M, Nitschke T, Massey B, Daniels S, Grande B, Katzandjian M, Dikeman K: Rehabilitation of swallowing by exercise in tube-fed patients with pharyngeal dysphagia secondary to abnormal UES opening. Gastroenterology 2002; 122:1314-1321.

256 Crary MA, Carnaby GD, Groher ME Helseth E: Functional benefits of dysphagia therapy using adjunctive sEMG biofeedback. Dysphagia 2004;19:160-116.

-257 Prosiegel M, Heintze M, Wagner-Sonntag E, Hannig C, Wuttge-Hannig A, Yassouridis A: Deglutition disorders in neurological patients. A prospective study of diagnosis, pattern of impairment, therapy and outcome. Nervenarzt 2002;73:364-370.

258 Calcagno P, Ruoppolo G, Grasso MG, De Vincentiis M, Paolucci S: Dysphagia in multiple sclerosis - prevalence and prognostic factors. Acta Neurol Scand 2002;105: 40-43.

259 Prosiegel M, Schelling A, Wagner-Sonntag E: Dysphagia and multiple sclerosis. Int MS J 2004;11:22-31.

260 Eisen GM, Baron TH, Dominitz JA, Faigel DO, Goldstein JL, Johanson JF, Mallery JS, Raddawi HM, Vargo JJ, Waring JP, Fanelli RD, Wheeler-Harbough J: Complications of upper GI endoscopy. Gastrointest Endosc 2002;55:784-793.

261 Loeser C, Foelsch UR: Guidelines for treatment with percutaneous endoscopic gastrostomy. German Society of Digestive and Metabolic Diseases. Z Gastroenterol 1996; 34:404-408.

262 Miller RG, Rosenberg JA, Gelinas DF, Mitsumoto H, Newman D, Sufit R, Borasio GD, Bradley WG, Bromberg MB, Brooks BR, Kasarskis EJ, Munsat TL, Oppenheimer EA: Practice parameter: the care of the patient with amyotrophic lateral sclerosis (an evidence-based review): report of the Quality Standards Subcommittee of the American Academy of Neurology: ALS Practice Parameters Task Force. Neurology 1999;52: 1311-1323. 
263 Norton B, Homer-Ward M, Donnelly MT, Long RG, Holmes GK: A randomised prospective comparison of percutaneous endoscopic gastrostomy and nasogastric tube feeding after acute dysphagic stroke. $\mathrm{Br}$ Med J 1996;312:13-16.

-264 Sanders DS, Carter MJ, D’Silva J, James G, Bolton RP, Willemse PJ, Bardhan KD: Percutaneous endoscopic gastrostomy: a prospective audit of the impact of guidelines in two district general hospitals in the United Kingdom. Am J Gastroenterol 2002;97: 2239-2245.

265 The FOOD Trial Collaboration: Effect of timing and method of enteral tube feeding for dysphagic stroke patients (FOOD): a multicentre randomised controlled trial. Lancet 2005;365:764-772.
266 Park RH, Allison MC, Lang J, Spence E, Morris AJ, Danesh BJ, Russell RI, Mills PR: Randomised comparison of percutaneous endoscopic gastrostomy and nasogastric tube feeding in patients with persisting neurological dysphagia. Br Med J 1992;304: 1406-1409.

267 Finucane TE, Bynum JP: Use of tube feeding to prevent aspiration pneumonia. Lancet 1996;348:1421-1424.

268 Ellies M, Laskawi R, Rohrbach-Volland S, Arglebe $\mathrm{C}$, Beuche $\mathrm{W}$ : Botulinum toxin to reduce saliva flow: selected indications for ultrasound-guided toxin application into salivary glands. Laryngoscope 2002;112: 82-86.
269 Giess R, Naumann M, Werner E, Riemann R, Beck M, Puls I, Reiners C, Toyka KV: Injections of botulinum toxin A into the salivary glands improve sialorrhoea in amyotrophic lateral sclerosis. J Neurol Neurosurg Psychiatry 2000;69:121-123.

$>270$ Ondo WG, Hunter C, Moore W: A doubleblind placebo controlled trial of botulinum toxin B for sialorrhoea in Parkinson's disease. Neurology 2004;62:37-40.

271 Chiu MJ, Chang YC, Hsiao TY: Prolonged effect of botulinum toxin injection in the treatment of cricopharyngeal dysphagia: case report and literature review. Dysphagia 2004;19:52-57.

272 Engelsen BA, Gronning M: Epileptic seizures in patients with multiple sclerosis. Is the prognosis of epilepsy underestimated? Seizure 1997;6:377-382. 